\title{
Pathways for minimal and zero liquid discharge with enhanced reverse osmosis technologies: Module-scale modeling and techno-economic assessment
}

\author{
Adam A. Atia ${ }^{\text {a,b }}$, Ngai Yin Yip ${ }^{\text {a,c }}$, Vasilis Fthenakis ${ }^{a, b, *}$ \\ ${ }^{a}$ Department of Earth and Environmental Engineering, Columbia University, New York 10027-6623, United States \\ ${ }^{\mathrm{b}}$ Center for Life Cycle Analysis, Columbia University, New York 10027-6623, United States \\ ${ }^{\mathrm{c}}$ Columbia Water Center, Columbia University, New York 10027-6623, United States
}

\section{H I G H L I G H T S}

- Module-scale, cost optimization models were developed for LSRRO, COMRO and OARO.

- We considered desalinating feedwater with $70 \mathrm{~g} / \mathrm{L}$ TDS at $75 \%$ water recovery.

- LCOW and SEC results ranged from 5.1 to $7.9 \$ / \mathrm{m}^{3}$ and 10.3 to $28.9 \mathrm{kWh} / \mathrm{m}^{3}$, respectively.

- OARO has the lowest LCOW, COMRO has the highest LCOW, and LSRRO has the highest SEC.

- COMRO can achieve water recovery at high feed salinities without multiple stages.

\section{A B S T R A C T}

While mechanical vapor compression is typically applied for the concentration of brine, new approaches that are less costly and less energy intensive are needed to facilitate minimal and zero liquid discharge. Several variations of reverse osmosis for high-salinity desalination and increasing recovery rates beyond the pressure limitation of conventional RO have been proposed in the literature. The promise of these enhanced RO approaches entails a reduction in energy consumption when compared with thermal desalination methods. In this paper, low-salt rejection reverse osmosis (LSRRO), cascading osmotically mediated reverse osmosis (COMRO), and osmotically assisted reverse osmosis (OARO) were comparatively assessed via module-scale, cost optimization models to gain an accurate perspective of the performance differences between each of these configurations. We quantified the optimal levelized cost of water (LCOW) of each technology for the case of desalinating feedwater at $70 \mathrm{~g} / \mathrm{L}$ at $75 \%$ recovery, which would result in a brine concentration near $250 \mathrm{~g} / \mathrm{L}$, a level that allows further treatment with crystallizers. For baseline scenarios, LCOW results for LSRRO, COMRO, and OARO were $6.63,7.90$, and $5.14 \$ / \mathrm{m}^{3}$ of product water, respectively, while the corresponding specific energy consumption (SEC) values were $28.9,12.8$, and $10.3 \mathrm{kWh} / \mathrm{m}^{3}$. A sensitivity analysis is also presented.

Keywords

Brine management

Minimal liquid discharge

Zero discharge

Zero liquid discharge

Osmotically assisted reverse osmosis

High-salinity desalination

\section{Introduction}

To ensure the sustainable availability of water for global population, the environment, and industry, unconventional and alternative water sources, such as seawater, brackish water, and wastewaters from municipal and industrial sectors, will have to be relied upon to meet the challenge. Desalination technology can treat these alternative water sources and produces about 95.4 million $\mathrm{m}^{3}$ /day of fresh water globally, but the associated generation of brine is about 141.5 million $\mathrm{m}^{3}$ /day $[1,2]$. Thus, brine management presents a significant barrier for further adoption, especially for inland desalination [3]. In the case of coastal seawater plants, the typical approach is ocean disposal via discharge outfalls with diffusers that promote mixing to dilute and release brine into offshore mixing zones [4,5]. Meanwhile, current brine management options for inland desalination plants include deep-well injection, evaporation ponds, surface and sewer discharge, land application, and

\footnotetext{
* Corresponding author at: Department of Earth and Environmental Engineering, Columbia University, New York 10027-6623, United States.

E-mail address: vmf5@columbia.edu (V. Fthenakis).
} 
brine concentration for minimum liquid discharge (MLD) and zero liquid discharge (ZLD) applications [6]. While ZLD is the most beneficial approach to minimize the environmental impacts of brine release, it is also energy intensive and costly to a degree that limits widescale implementation.

Although reverse osmosis (RO) is the state-of-the-art technology for brackish and seawater desalination due to its high energy efficiency and cost-effectiveness, the osmotic pressure of hypersaline brine $(\geq 70 \mathrm{~g} / \mathrm{L})$ exceeds the maximum pressure limit of typical RO membranes, signaling a need for technologies that can circumvent such pressure limitations. Thermal desalination technologies are not inhibited by pressure limitations, but they require a phase-change from liquid to vapor that significantly increases energy requirements mainly because of the latent heat of vaporization $\left(>630 \mathrm{kWh} / \mathrm{m}^{3}\right)$ [7,8]. Mechanical vapor compression (MVC) brine concentrators are currently the state-of-theart technology for concentrating hypersaline brine, typically up to $\approx 250 \mathrm{~g} / \mathrm{L}$ total dissolved solids (TDS), which can then be passed to crystallizers for zero-liquid-discharge $[9,10]$. While MVC possesses a high recovery of latent heat and can achieve a specific energy consumption in the range of $20-40 \mathrm{kWh}_{\mathrm{e}} / \mathrm{m}^{3}$ of feedwater [9-11], the technology remains energy-intensive, primarily uses electrical energy for vapor compression, and requires stainless steel and titanium materials for avoiding corrosion, resulting in high capital cost. Furthermore, based on estimates of second-law efficiencies for zero-liquid-discharge, MVC brine concentrators were shown to be less than half as efficient ( $8.5 \%$ and $11.6 \%$ second-law efficiency for single- and two-stage MVC) as multi-effect evaporators used for crystallization $(24.4 \%$ second-law efficiency) [12], indicating that efforts should focus more on improving the energy efficiency of the brine concentration step in zeroliquid-discharge applications. Thus, there is an opportunity for novel desalination technologies to be tailored to treating feedwater concentrations between 70 and $250 \mathrm{~g} / \mathrm{L}$ [7,9]. Other emerging technologies that have the potential to facilitate MLD and ZLD include membrane distillation [10,13-15], forward osmosis with draw recovery [16], temperature-swing solvent extraction [8,17], electrodialysis [18,19], high-pressure RO [7], and osmotically assisted RO (OARO) [20-22].

Recently proposed variations of OARO for treating hypersaline brine, hereafter referred to as "enhanced RO," include low-salt-rejection reverse osmosis (LSRRO) [23] and cascading osmotically mediated reverse osmosis (COMRO) [24]. The promise behind these enhanced RO approaches is a reduction in energy consumption when compared with thermal desalination methods. OARO and COMRO overcome the maximum pressure limits of conventional RO by using bilateral countercurrent (BCC) modules that pass saline water across the permeate channel of the membrane, which reduces the osmotic pressure difference across the membrane. LSRRO incorporates low-salt-rejection (LSR) membrane modules (e.g., "loose" nanofiltration membranes), downstream of a conventional RO module. In this process, the pressure limitation is overcome by enabling a saline permeate stream via LSR membranes, once again reducing the transmembrane osmotic pressure and thus the required hydraulic pressure. Unlike OARO and COMRO though, this approach does not use BCC modules; the system follows the same crossflow operation of typical RO processes. Due to these differences, concentration polarization effects are expected to vary between these technologies, and module-scale modeling is critical for a more accurate assessment of technical performance and comparison. Although the working principles for COMRO [24] and LSRRO [23] have been previously reported, these studies lack module-scale modeling that incorporate inefficiencies. Moreover, the technical performance of LSRRO, COMRO, and OARO has not been quantitatively compared in detail. Lastly, while a cost optimization analysis has shown the potential of OARO to be cost-competitive with MVC for high-salinity desalination [11], detailed cost optimization analyses have not been reported for COMRO and LSRRO.

In this study, we comparatively assessed the technical performance and levelized cost of water (LCOW) for LSRRO, COMRO, and OARO.
First, to elucidate the extent to which each technology can treat highsalinity feeds, the theoretical recovery-rate limit for each technology was determined as a function of feed salinity, based on maximum pressure constraints and ideal assumptions. Subsequently, we developed module-scale optimization models for each technology and set the objective function to minimize the LCOW, which enabled a detailed comparison and breakdown of the optimal LCOW, the associated specific energy consumption (SEC), and other decision variables. Next, we considered the case of treating feedwater at $70 \mathrm{~g} / \mathrm{L}$ TDS and concentrating it to $250 \mathrm{~g}$ / L TDS (the opportunity regime for brine concentration) and solved for system design and operational parameters to achieve the minimal LCOW for each technology. Lastly, we conducted sensitivity analyses to gain further insights on the effects of several design and cost parameters on the LCOW. In doing so, this work provides guidance on the design of newly proposed enhanced RO configurations for hypersaline desalination and minimal/zero liquid discharge and identifies key areas for improvement and opportunity.

\section{Theory \& methodology}

\subsection{Overview of enhanced RO technologies for minimal/zero liquid discharge}

Conventional reverse osmosis has an intrinsic limitation regarding the transmembrane osmotic pressure. Once the concentration of the feed exceeds a certain maximum, typically in the range of 70-80 g/L TDS, the osmotic pressure difference between the feed and permeate channels increases so much so that the required applied pressure exceeds the maximum allowable pressure of membranes and other system components. Although specialized membrane modules for high-pressure RO can enable higher feed pressures than conventional RO [7], operating at such high pressures (e.g., 120-150 bar) is expected to be more challenging and costly in terms of practical implementation [25]. An alternative approach to raising the maximum allowable pressure of membrane modules is to reduce the transmembrane osmotic pressure. In this paper, we refer to such approaches as enhanced RO.

Several variations of enhanced RO are reported in the literature. Low-pressure high-recovery (LPHR) RO combines reverse osmosis and nanofiltration modules in a multi-stage configuration, comprising primary and secondary treatment units, as reported by Ahunbay [26]. The $\mathrm{RO}$ units serve as primary, upstream treatment units, while NF and a downstream RO unit are used to recirculate concentrate back to the primary RO units. The LPHRRO concept draws from previous studies that also propose multi-stage configurations. One variation of this approach is referred to as energy-efficient RO (EERO) by Chong and Krantz [27], while another study refers to this approach as multi-stage RO (MSRO) [28]; the term also describes RO stages followed by NF stages where NF permeate is recirculated to the feed of previous RO stages. The study shows that MSRO can decrease specific energy consumption and increase recovery rates by reducing transmembrane osmotic pressure. The LSRRO concept proposed by Wang et al. [23] can technically be categorized with the aforementioned LPRHRO, MSRO, and EERO concepts [26-28]. In LSRRO, a primary RO train receives incoming feedwater and supplies its brine to downstream, low-rejection NF stages, where the NF permeate from each stage is recirculated to the feed stream of the previous stage.

Of all the enhanced RO processes proposed thus far, OARO has been examined more extensively in terms of technical performance [20,21] and cost [11]. Park et al. essentially studied OARO but referred to the process as draw solution assisted RO (DSARO) [29]. More recently, Peters \& Hankins proposed the use of thermo-responsive draw solutions in OARO and made comparisons with FO, LSRRO, and conventional OARO [30]. OARO has also been referred to as counterflow RO (CFRO) by Bouma \& Lienhard [22]; the authors analyzed two variations of CFRO and proposed a new alternative called split-feed CFRO. One of the variations, referred to as feed-through CFRO, is the same configuration as 
COMRO and was proposed as an alternative concept for treating highsalinity feedwaters by Chen and Yip [24,31]. The maximum operating pressure, analytical expressions for the SEC, and an assessment of potential energy savings were compared with OARO and direct-pass RO. In comparison to OARO, COMRO can enable energy savings by adding bilateral countercurrent (BCC) modules in series. However, the limit at which COMRO can recover water from high-salinity waters remains unclear. Moreover, adding BCC modules in series would not increase the maximum brine concentration and recovery rate for a given feed concentration. In terms of cost, a recent study considers a hybrid system that integrates forward osmosis (FO) followed by COMRO to treat RO brine from a copper production facility in Huelva, Spain [32]. The authors performed an experimental and technoeconomic analysis, demonstrating the feasibility of achieving $75 \%$ recovery from a feed of $\approx 41 \mathrm{~g} / \mathrm{L}$ TDS; they estimated an SEC of $6.59 \mathrm{kWh} / \mathrm{m}^{3}$ for COMRO and a total LCOW of $\$ 6.05 / \mathrm{m}^{3}$ (accounting for the FO system).

Of the proposed enhanced RO processes found in the literature, LSRRO, COMRO, and OARO were selected for comparative analysis due to their generality and scalability.

\subsection{Working principles of LSRRO, COMRO, and OARO}

This section summarizes the basic principles of LSRRO [23], COMRO [24], and OARO [20]; the corresponding details can be found in the cited literature. Fig. 1 shows a general diagram of each system. Fig. 2 shows multiple-stage configurations of each system.

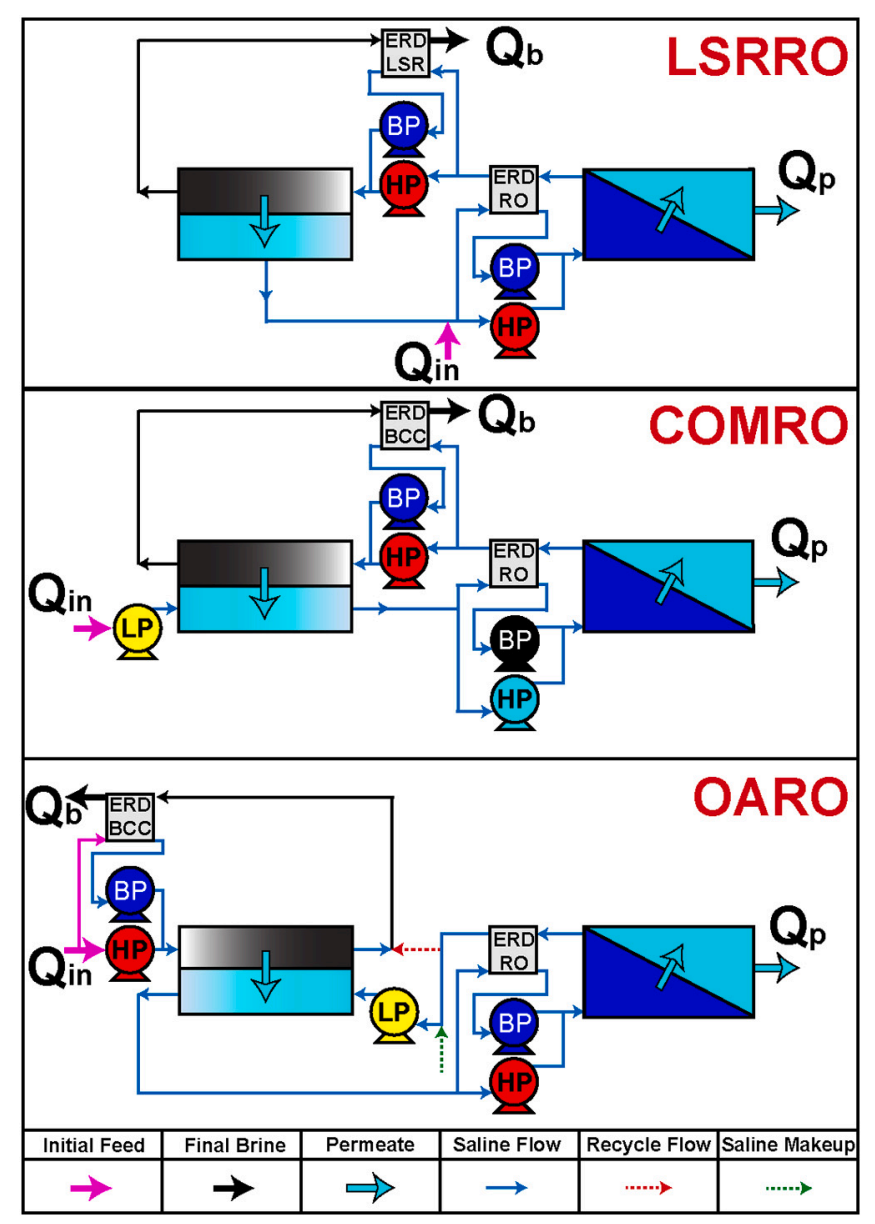

Fig. 1. Enhanced RO process configurations considered in this study. HP, BP, and LP stand for high-pressure, booster, and low-pressure pumps, respectively. ERD indicates an energy recovery device corresponding to either a bilateral countercurrent (BCC), low-salt rejection (LSR), or conventional RO train. $\left(\mathrm{Q}_{\text {in }}\right.$ : initial feedwater flow; $Q_{b}$ : exiting brine flow; $Q_{p}$; final permeate flow).
In LSRRO (Fig. 1, top), the incoming feedwater enters a conventional RO module; the RO concentrate is fed to a low-salt-rejection (LSR) membrane module that sends its saline permeate back to the feed of the RO module. Since the LSR membrane facilitates salt passage and allows the permeate channel to have a higher salt concentration and thus a higher osmotic pressure than the permeate channel of conventional RO (typically $\leq 0.5 \mathrm{~g} / \mathrm{L}$ ), the transmembrane osmotic pressure can be reduced, enabling treatment of high-salinity water and increased recovery.

In COMRO (Fig. 1, center), the incoming feedwater enters the permeate channel of a bilateral countercurrent (BCC) membrane module; this feedwater is diluted within the BCC module and is fed to a conventional RO module at a concentration low enough to be feasible for water recovery. Concentrate from the conventional RO unit is fed to the feed-channel inlet of the BCC module, where water is further extracted from the brine for the purpose of diluting new incoming feedwater. Overall, COMRO depends on BCC modules that operate based on a reduced transmembrane osmotic pressure for the purpose of diluting the feed to treatable levels for conventional RO.

In OARO (Fig. 1, bottom), the incoming feedwater enters the feed channel of a BCC module where water permeates across the membrane and the resulting concentrate exits the system; the permeate dilutes a saline sweep solution in the permeate channel of the BCC. The diluted sweep solution exits the BCC permeate channel and is fed into a conventional RO module. Like COMRO, OARO uses the BCC module to separate water from high-salinity feeds and dilute the feed concentration to levels that can be treated with conventional RO.

Although OARO and COMRO both implement BCC modules, OARO utilizes a saline sweep solution to reduce the transmembrane osmotic pressure, while COMRO uses the hypersaline brine feed itself as the saline solution to reduce transmembrane osmotic pressure. However, due to the use of BCC modules, both COMRO and OARO would experience external and internal concentration polarization, which would increase the transmembrane osmotic pressure [33]; i.e., external concentration polarization (ECP) increases concentration at the feed-side of the membrane interface, and internal concentration polarization (ICP) decreases the concentration at the permeate-side of the membrane interface. Chen et al. suggested that, at high salinities, the effect of ICP should be reduced because salt flux increases disproportionately with water flux [31]. Nevertheless, there would still be a detrimental impact on permeate flux. On the other hand, since LSRRO does not use BCC modules and instead incorporates typical crossflow operation found in conventional RO, LSR modules would only experience ECP in the feed channel. Wang et al. point out that, because of countercurrent operation, OARO and COMRO would require membranes with a reduced structural parameter (effective thickness) and more dense permeate spacers to avoid membrane rupture, while LSRRO could use readily available membrane modules [23]. However, they also describe the need for very low salt-rejection rates (as low as $4 \%$ in presented scenarios), which would require modified or newly developed membranes to meet the promise of LSRRO.

\subsection{Recovery rate limit}

To clarify the extent to which LSRRO, COMRO, and OARO could treat high-salinity feedwaters, the theoretical recovery rate limit can be estimated under simplifying assumptions. Assuming the van't Hoff relationship for osmotic pressure, $100 \%$ salt rejection, neglecting concentration polarization effects and pressure losses, and setting the applied pressure equal to the osmotic pressure of the concentrate, the theoretical maximum brine concentration for conventional $\mathrm{RO}, \mathrm{C}_{\mathrm{b}, \max }$, can be expressed as

$C_{b, \max }=\frac{\Delta P_{\max }}{v R T / M W}$ 


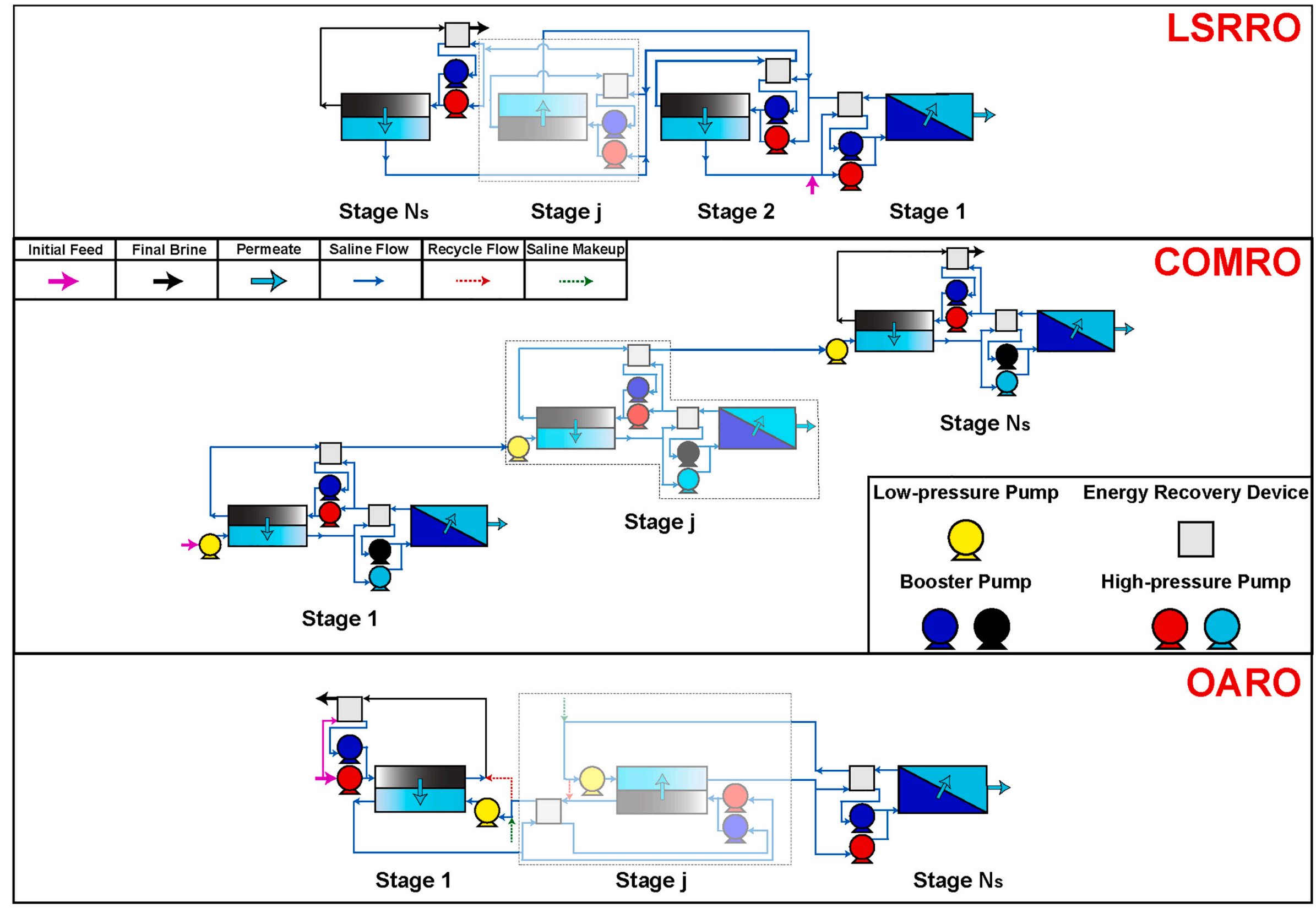

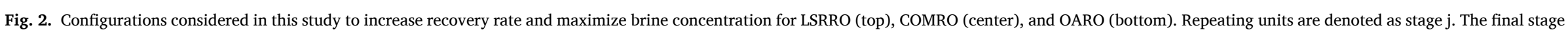
is denoted as $\mathrm{N}_{\mathrm{s}}$. 
where $\Delta \mathrm{P}_{\max }$ is the maximum applied pressure, $v$ is the van't Hoff dissociation factor, and MW is the molecular weight (of $\mathrm{NaCl}$ ). The following derivations for each technology can be determined by using the total mass and solute balance equations to solve for recovery rate as a function of feed concentration and substituting for the final brine concentration, $\mathrm{C}_{\text {out }}$ (i.e., $\mathrm{R}=1-\mathrm{C}_{\text {in }} / \mathrm{C}_{\text {out }}$ ).

For COMRO, the theoretical recovery rate limit as a function of feed salinity can be expressed as

$R_{T, \max }=1-\frac{C_{\text {in }}}{C_{\text {in }}+N_{\text {COMRO }} C_{b, \max }}$

From this relationship, we observe that the theoretical recovery rate limit for COMRO depends on the feed concentration $\left(\mathrm{C}_{\text {in }}\right)$ and the number of COMRO stages in series $\left(\mathrm{N}_{\mathrm{COMRO}}\right)$. From another perspective, the denominator, which is equal to the final brine concentration, is dependent on $\mathrm{N}_{\text {COMro }}$ and $\mathrm{C}_{\mathrm{in}}$, and thus the recovery rate limit is inversely proportional and nonlinearly related to the feed concentration, i.e., $\mathrm{R}_{\mathrm{T}, \max } \alpha \mathrm{C}_{\mathrm{in}}^{-1}$.

The theoretical recovery rate limit for LSRRO and OARO can be expressed as

$R_{T, \max }=1-\frac{C_{\text {in }}}{N_{\text {OARO } \mid L S R R O} C_{b, \max }}$

Here, the number of stages is denoted by $\mathrm{N}_{\text {OARO|LSRRO, and unlike }}$ COMRO, the final brine concentration is primarily dependent on the number of stages, while the relationship between recovery rate limit and feed concentration is linear. Furthermore, for LSRRO, in addition to assuming $100 \%$ salt rejection for the conventional RO module, salt rejection of the LSR modules is assumed to approach zero.

Fig. 2 shows how we denote stages in this study for LSRRO, COMRO, and OARO, which are configured here in a way that increases recovery rate and intensifies the concentration of brine. There is an important discrepancy concerning how stages are counted in COMRO compared with previous work on COMRO [24]. In this study, one COMRO stage comprises a BCC module followed by a downstream conventional RO module. The brine exiting the BCC feed channel would then be passed to a subsequent COMRO stage (i.e., COMRO stages are placed in series.) Meanwhile, OARO and LSRRO require the addition of BCC and LSR modules, respectively, between the first stage and the final conventional RO stage.

\subsection{Optimization model}

Module-scale, cost-optimization models were developed for LSRRO, COMRO, and OARO and solved using the AP Monitor Optimization Suite [34]. An overview of the optimization model framework is provided in Fig. 3. In each model, the objective function is to minimize the LCOW, and the optimal LCOW is obtained by entering the feed concentration, the water recovery rate, and the number of stages (additional input parameters shown later in Tables 1 and 2). To determine the number of stages, we iteratively change the number of stages for each run of the
Table 1

Baseline technical parameters used in optimization cases (except for A and B values of LSR and BCC membranes, values adopted from [11]).

\begin{tabular}{ll}
\hline Parameter & Value \\
\hline Water permeability of LSR membrane [m/bar/s] & $4.167 \times 10^{-7}$ \\
Water permeability of BCC membranes [m/bar/s] & $4.167 \times 10^{-7}$ \\
Solute permeability of LSR membrane [m/s] & $3.0699 \times 10^{-6}$ \\
Solute permeability of BCC membranes [m/s] & $1.2469 \times 10^{-8}$ \\
Water permeability of conventional RO membranes [m/bar/s] & $4.2 \times 10^{-7}$ \\
Solute permeability of conventional RO membranes [m/s] & $3.5 \times 10^{-8}$ \\
Structural parameter of BCC membranes [microns] & 1200 \\
Maximum pressure constraint of BCC and LSR membranes [bar] & 65 \\
Maximum pressure constraint of conventional RO membranes & 85 \\
$\quad$ bar] & 20 \\
Feedwater temperature [ $\left.{ }^{\circ} \mathrm{C}\right]$ & 0.5 \\
Maximum final permeate TDS [g/L] & 0.9 \\
Load factor [-] & 2 \\
Feed \& permeate channel height for all technologies [mm] & 0.75 \\
Spacer porosity for all technologies [-] & 0.75 \\
Pump efficiency for all pumps [-] & 0.9 \\
ERD efficiency for all devices [-] & 468 \\
Feed flow rate (m ${ }^{3} /$ day) & \\
\hline
\end{tabular}

Table 2

Baseline financial parameters used in optimization cases [11].

\begin{tabular}{ll}
\hline Parameter & Value \\
\hline Pump unit cost $\left[\$ / \mathrm{bar} / \mathrm{m}^{3} / \mathrm{h}\right]$ & 53 \\
ERD capital cost $[\$]\left(\mathrm{Q}[=] \mathrm{m}^{3} / \mathrm{h}\right)$ & $C_{E R D}=3134.7 Q^{0.58}$ \\
Conventional RO membrane cost $\left[\$ / \mathrm{m}^{2}\right]$ & 30 \\
Bilateral countercurrent membrane $\operatorname{cost}\left[\$ / \mathrm{m}^{2}\right]$ & 50 \\
Low-salt-rejection membrane cost $\left[\$ / \mathrm{m}^{2}\right]$ & 50 \\
Cost of electricity $[\$ / \mathrm{kWh}]$ & 0.07 \\
Discount rate $[\%]$ & 7.8 \\
Lifetime [years] & 20 \\
Annual chemical costs $[\$]$ & $0.01 *$ CAPEX \\
Annual labor \& maintenance costs $[\$]$ & $0.02 *$ CAPEX \\
Practical investment factor $[-]$ & 1.6 \\
\hline
\end{tabular}

optimization model. The optimization results include membrane area, pump and ERD capacities, flux and other hydraulic parameters along the membrane length, specific energy consumption, and a breakdown of the LCOW.

Module-scale modeling was implemented via a 1D finite difference approach as proposed in [11] and [35]. In terms of model accuracy, Bartholomew et al. conducted a detailed assessment of computational accuracy for membrane process models which included RO and OARO [35]. In this work, the authors showed that less than $1 \%$ error in average water flux can be achieved with 5 nodes; using 2 nodes resulted in errors less than $5 \%$ for OARO and RO. Thus, in our models, we used 3 nodes for all cases to reduce computational time. Moreover, Bartholomew et al. found that some of the largest errors in average water flux estimations arose from simplifying assumptions rather than the number of nodes. For example, assuming no salt flux in OARO can result in more than $30 \%$

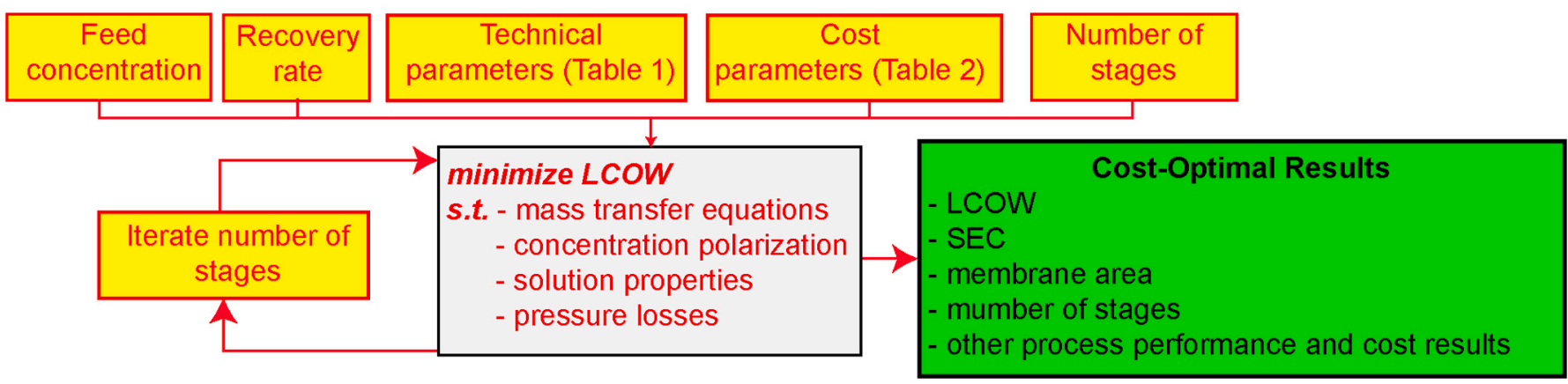

Fig. 3. Overview of optimization model framework. 
error. Meanwhile, assuming an ideal solution resulted in more than $10 \%$ error for RO. Our models account for pressure drop across the membrane length, external and internal concentration polarization, nonlinear osmotic pressure as a function of concentration at high salinities, equipment efficiencies, and variable density with salinity.

The total mass and solute equations which differentiate LSRRO, COMRO, and OARO from each other are listed below, namely, in terms of mass inlet, outlet, and recirculation conditions. Other fundamental equations, which are shared across technologies (e.g., solution properties, mass transfer, pressure loss), are summarized in the Supplementary material. Variables are either nodal or inter-nodal, where $i$ is either the node or inter-nodal edge, and $j$ is the stage. Furthermore, the subscript $f$ represents the feed channel and $\mathrm{p}$ is the permeate channel. In general, variables are denoted here in the form of $X_{\text {channel, } i, j}$ (e.g., $\mathrm{M}_{\mathrm{f}, 0,1}$ would represent the mass flow in the feed channel, at node 0 , stage 1 .)

\subsubsection{Mass equations}

The inlet and outlet conditions for solution mass flows of LSRRO are as follows. $\mathrm{M}_{\mathrm{f}, 0,1}$, the feedwater entering the first stage (i.e., the conventional RO stage) is equal to the feedwater entering the system, $M_{i n}$, plus $M_{p, N, 2}$, the saline permeate exiting the second stage (i.e., first LSR stage).

$M_{f, 0,1}=M_{\text {in }}+M_{p, N, 2}$

From the second stage to the penultimate stage, the feedwater mass into stage $j, M_{f, 0, j}$, is equal to the sum of the concentrate exiting the previous stage, $\mathrm{M}_{\mathrm{f}, \mathrm{N}, \mathrm{j}-1}$, and the saline permeate exiting the subsequent stage, $\mathrm{M}_{\mathrm{p}, \mathrm{N}, \mathrm{j}+1}$.

$M_{f, 0, j}=M_{f, N, j-1}+M_{p, N, j+1}, \forall j:\left[2, N_{s}-1\right], N_{s}>2$

The feedwater mass flow entering the last stage, $\mathrm{M}_{\mathrm{f}, 0 \text {, Ns }}$, is equal to that of the concentrate leaving the penultimate stage, $\mathrm{M}_{\mathrm{f}, \mathrm{N}, \mathrm{Ns}-1}$.

$M_{f, 0, N_{s}}=M_{f, N, N_{s}-1}$

Correspondingly, the solute mass inlet and outlet conditions for LSRRO at the first, second through penultimate, and last stage, respectively, are

$$
\begin{aligned}
& M_{f, 0,1} X_{f, 0,1}=M_{i n} X_{i n}+M_{p, N, 2} X_{p, N, 2} \\
& M_{f, 0, j} X_{f, 0, j}= M_{f, N, j-1} X_{f, N, j-1}+M_{p, N, j+1} X_{p, N, j+1}, \\
& \forall j:\left[2, N_{s}-1\right], N_{s}>2 \\
& M_{f, 0, N_{s}} X_{f, 0, N_{s}}=M_{f, N, N_{s}-1} X_{f, N, N_{s}-1}
\end{aligned}
$$

where $\mathrm{X}$ is the salt mass fraction at the respective channel, inter-nodal edge, and stage.

Additionally, mass flow at the permeate channel inlet of each stage is initialized at $M_{p, 0, j}=0$.

In COMRO systems, every stage comprises a BCC train and an RO train and those are denoted by individual subscripts below. The feedwater going into the system, $\mathrm{M}_{\mathrm{in}}$, enters the permeate channel inlet of

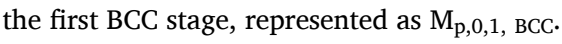

$M_{\text {in }}=M_{p, 0,1, B C C}$

The diluted mass exiting the permeate channels of the BCC train at

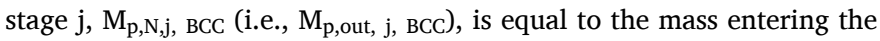
feed channels of the conventional RO train at stage $j, M_{f, 0}$, , Ro (i.e., $M_{f}$, in, $\mathrm{j}$, RO).

$M_{p, o u t, j, B C C}=M_{p, N, j, B C C}=M_{f, i n, j, R O}=M_{f, 0, j, R O}, \forall j$

The concentrated mass exiting the feed channels of the RO train at stage $j, M_{f, N}, j$, Ro (i.e., $M_{f, o u t, j, R O}$ ), is equal to the mass entering the feed

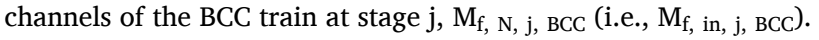

$M_{f, o u t, j, R O}=M_{f, N, j, R O}=M_{f, i n, j, B C C}=M_{f, N, j, B C C}, \forall j$
From the first stage to the penultimate stage, the concentrated mass

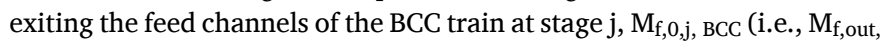
$\mathrm{j}, \mathrm{BCC}$ ), is equal to the mass entering the permeate channels of the BCC train at the subsequent stage, $M_{p, 0, j+1}$, BCC (i.e., $M_{p}$, in, $j+1, B C C$ ).

$M_{f, o u t, j, B C C}=M_{f, 0, j, B C C}=M_{p, i n, j+1, B C C}=M_{p, 0, j+1, B C C}$,
$\forall j:\left[1, N_{s}-1, N_{s}>1\right.$

At the final stage, the concentrated mass exiting the feed channels of the BCC train at stage $\mathrm{N}_{s}, \mathrm{M}_{\mathrm{f}, 0, \mathrm{Ns}}$, BCC (i.e., $\mathrm{M}_{\mathrm{f}, \text { out,Ns, BCC) is the final }}$ brine.

$M_{f, \text { out }, N_{s}, B C C}=M_{f, 0, N_{s}, B C C}$

Correspondingly, the solute mass inlet and outlet conditions for COMRO are

$$
\begin{gathered}
M_{i n} X_{i n}=M_{p, 0,1, B C C} X_{p, 0,1, B C C} \\
M_{p, N, j, B C C} X_{p, N, j, B C C}=M_{f, 0, j, R O} X_{f, 0, j, R O}, \forall j \\
M_{f, N, j, R O} X_{f, N, j, R O}=M_{f, N, j, B C C} X_{f, N, j, B C C}, \forall j \\
M_{f, 0, j, B C C} X_{f, 0, j, B C C}=M_{p, 0, j+1, B C C} X_{p, 0, j+1, B C C}, \\
\forall j:\left[1, N_{s}-1\right], N_{s}>1
\end{gathered}
$$

For OARO, the feedwater going into the system, $\mathrm{M}_{\mathrm{in}}$, enters the feed channel inlet of the first stage, represented as $\mathrm{M}_{\mathrm{f}, 0,1}$.

$M_{\text {in }}=M_{f, 0,1}$

The final brine exiting the system, $M_{\text {out }}$, is equal to the concentrate exiting the first stage, $M_{f, N}, 1$, plus any disposal streams, $M_{d, j}$, from subsequent stages.

$M_{\text {out }}=M_{f, N, 1}+\sum_{j=1}^{N_{s}-1} M_{d, j}$

These disposal streams are extractions from the concentrate exiting the feed channel outlet of subsequent stages (i.e., from the second stage through the final stage). In this study, we only consider one disposal stream from the feed outlet of the second stage. Likewise, from stage 2 to stage $N_{s}$, a recycle stream, $M_{r, j}$, is extracted from the concentrate exiting the feed channel outlet of stage $\mathrm{j}$ and is fed to the sweep inlet of the previous stage, stage $j-1$. Thus, we consider $M_{d}=M_{r, 1}$ and the final brine is now

$M_{\text {out }}=M_{f, N, 1}+M_{r, 1}$

Additionally, any saline makeup solution, $\mathrm{M}_{\mathrm{a}, \mathrm{j}}$, that is required is also added at the sweep inlet of a given BCC stage. Thus the saline sweep solution entering the permeate channel of each BCC stage, $\mathrm{M}_{\mathrm{p}, \mathrm{N}, \mathrm{j}}$, is

$\begin{aligned} M_{p, N, j}= & M_{f, N, j+1}-M_{r, j}+M_{r, j+1}+M_{a, j}, \\ & \forall j:\left[1, N_{s}-2\right], N_{s}>2\end{aligned}$

$M_{p, N, N_{s}-1}=M_{f, N, N_{s}}-M_{r, N_{s}-1}+M_{a, N_{s}-1}$

with the corresponding solute balances expressed by

$$
\begin{gathered}
M_{p, N, j} X_{p, N, j}= \\
\left(M_{f, N, j+1}-M_{r, j}\right) X_{f, N, j+1}+M_{r, j+1} X_{f, N, j+2}+M_{a, j} X_{a}, \\
\forall j:\left[1, N_{s}-2\right], N_{s}>2 \\
M_{p, N, N_{s}-1} X_{p, N, N_{s}-1}= \\
\left(M_{f, N, N_{s}}-M_{r, N_{s}-1}\right) X_{f, N, N_{s}}+M_{a, N_{s}-1} X_{a}
\end{gathered}
$$

From the second stage to the last stage, the mass flow entering the feed channels of stage $j, M_{f, 0, j}$, is equal to the mass flow of the saline sweep solution exiting the permeate channel of the previous stage $j-1$, $\mathrm{M}_{\mathrm{p}, 0, \mathrm{j}-1 \text {. }}$

$M_{f, i n, j}=M_{f, 0, j}=M_{p, 0, j-1}=M_{p, o u t, j-1}, \forall j:\left[2, N_{s}\right]$ 
Correspondingly, the system-level solute mass inlet and outlet conditions for OARO are

$M_{\text {in }} X_{\text {in }}=M_{f, 0,1} X_{f, 0,1}$

$M_{f, \text { out }} X_{f, \text { out }}=M_{f, N, 1} X_{f, N, 1}+M_{r, 1} X_{f, N, 2}$

The final permeate concentration for LSRRO, COMRO, and OARO can be obtained from Eqs. (29), (30), and (31), respectively:

$M_{p, f i n a l} X_{p, \text { final }}=M_{p, N, 1} X_{p, N, 1}$

$M_{p, f i n a l} X_{p, f i n a l}=\sum_{j=1}^{N_{s}} M_{p, N, j, R O} X_{p, N, j, R O}$

$M_{p, f i n a l} X_{p, f i n a l}=M_{p, N, N_{s}} X_{p, N, N_{s}}$

The solution and solute balances across the membrane feed and permeate channels, respectively, for LSRRO are

$M_{f, i, j}=M_{f, i-1, j}-\frac{A_{m, j}}{N}\left(\rho_{w} J_{w, i, j}+J_{s, i, j}\right), \forall j$

$M_{p, i, j}=M_{p, i-1, j}+\frac{A_{m, j}}{N}\left(\rho_{w} J_{w, i, j}+J_{s, i, j}\right), \forall j$

$M_{f, i, j} X_{f, i, j}=M_{f, i-1, j} X_{f, i-1, j}-\frac{A_{m, j}}{N} J_{s, i, j}, \forall j$

$M_{p, i, j} X_{p, i, j}=M_{p, i-1, j} X_{p, i-1, j}+\frac{A_{m, j}}{N} J_{s, i, j}, \forall j$

The solution and solute balances across the membrane feed and permeate channels, respectively, for BCC modules in COMRO are

$M_{f, i, j, B C C}=M_{f, i-1, j, B C C}+\frac{A_{m, j, B C C}}{N}\left(\rho_{w} J_{w, i, j, B C C}+J_{s, i, j, B C C}\right), \forall j$

$M_{p, i, j, B C C}=M_{p, i-1, j, B C C}+\frac{A_{m, j, B C C}}{N}\left(\rho_{w} J_{w, i, j, B C C}+J_{s, i, j, B C C}\right), \forall j$

$M_{f, i, j, B C C} X_{f, i, j, B C C}=M_{f, i-1, j, B C C} X_{f, i-1, j, B C C}+\frac{A_{m, j, B C C}}{N} J_{s, i, j, B C C}, \forall j$

$M_{p, i, j, B C C} X_{p, i, j, B C C}=M_{p, i-1, j, B C C} X_{p, i-1, j, B C C}+\frac{A_{m, j, B C C}}{N} J_{s, i, j, B C C}, \forall j$

and for RO modules in COMRO are

$M_{f, i, j, R O}=M_{f, i-1, j, R O}-\frac{A_{m, j, R O}}{N}\left(\rho_{w} J_{w, i, j, R O}+J_{s, i, j, R O}\right), \forall j$

$M_{p, i, j, R O}=M_{p, i-1, j, R O}+\frac{A_{m, j, R O}}{N}\left(\rho_{w} J_{w, i, j, R O}+J_{s, i, j, R O}\right), \forall j$

$M_{f, i, j, R O} X_{f, i, j, R O}=M_{f, i-1, j, R O} X_{f, i-1, j, R O}-\frac{A_{m, j, R O}}{N} J_{s, i, j, R O}, \forall j$

$M_{p, i, j, R O} X_{p, i, j, R O}=M_{p, i-1, j, R O} X_{p, i-1, j, R O}+\frac{A_{m, j, R O}}{N} J_{s, i, j, R O}, \forall j$

The solution balances across the membrane feed and permeate channels, respectively, for BCC stages in OARO are

$$
\begin{gathered}
M_{f, i, j}=M_{f, i-1, j}-\frac{A_{m, j}}{N}\left(\rho_{w} J_{w, i, j}+J_{s, i, j}\right), \\
\forall j:\left[1, N_{s}-1\right] \\
M_{p, i, j}=M_{p, i-1, j}-\frac{A_{m, j}}{N}\left(\rho_{w} J_{w, i, j}+J_{s, i, j}\right), \\
\forall j:\left[1, N_{s}-1\right] \\
M_{f, i, j} X_{f, i, j}=M_{f, i-1, j} X_{f, i-1, j}-\frac{A_{m, j}}{N} J_{s, i, j}, \\
\forall j:\left[1, N_{s}-1\right]
\end{gathered}
$$

$$
\begin{aligned}
M_{p, i, j} X_{p, i, j} & =M_{p, i-1, j} X_{p, i-1, j}-\frac{A_{m, j}}{N} J_{s, i, j}, \\
& \forall j:\left[1, N_{s}-1\right]
\end{aligned}
$$

and for the RO stage in OARO are

$M_{f, i, N_{s}}=M_{f, i-1, N_{s}}-\frac{A_{m, N_{s}}}{N}\left(\rho_{w} J_{w, i, N_{s}}+J_{s, i, N_{s}}\right)$

$M_{p, i, N_{s}}=M_{p, i-1, N_{s}}+\frac{A_{m, N_{s}}}{N}\left(\rho_{w} J_{w, i, N_{s}}+J_{s, i, N_{s}}\right)$

$M_{f, i, N_{s}} X_{f, i, N_{s}}=M_{f, i-1, N_{s}} X_{f, i-1, N_{s}}-\frac{A_{m, N_{s}}}{N} J_{s, i, N_{s}}$

$M_{p, i, N_{s}} X_{p, i, N_{s}}=M_{p, i-1, N_{s}} X_{p, i-1, N_{s}}+\frac{A_{m, N_{s}}}{N} J_{s, i, N_{s}}$

The system solution and solute mass balances for LSRRO (Eqs. (52), (53)), COMRO (Eqs. (54), (55)), and OARO (Eqs. (56), (57)), respectively, are

$M_{\text {in }}=M_{p, N, 1}+M_{f, N, N_{s}}$

$M_{\text {in }} X_{\text {in }}=M_{p, N, 1} X_{p, N, 1}+M_{f, N, N_{s}} X_{f, N, N_{s}}$

$M_{p, 0,1, B C C}=M_{f, 0, N_{s}, B C C}+\sum_{j=1}^{N_{s}} M_{p, N, j, R O}$

$M_{p, 0,1, B C C} X_{p, 0,1, B C C}=M_{f, 0, N_{s}, B C C} X_{f, 0, N_{s}, B C C}+\sum_{j=1}^{N_{s}} M_{p, N, j, R O} X_{p, N, j, R O}$

$M_{f, 0,1}+\sum_{j=1}^{N_{s}-1} M_{a, j}=M_{f, N, 1}+M_{r, 1}+M_{p, N, N_{s}}$

$M_{f, 0,1} X_{f, 0,1}+\sum_{j=1}^{N_{s}-1} M_{a, j} X_{a}=M_{f, N, 1} X_{f, N, 1}+M_{r, 1} X_{r, 1}+M_{p, N, N_{s}} X_{p, N, N_{s}}$

\subsubsection{Concentration polarization}

COMRO and OARO are affected by ECP in the feed channel and ICP in the permeate channel, resulting in an increase in the transmembrane osmotic pressure and a decrease in the net driving pressure. Thus, the expected water flux of counter-current modules in COMRO and OARO would be reduced. For LSRRO, only ECP would impact the permeate flux; ICP does not occur since flow moves perpendicularly away from the membrane surface [23].

Water flux, $J_{\mathrm{W}}$, and solute flux, $\mathrm{J}_{\mathrm{s}}$, can be expressed at each node i along the membrane and stage $\mathrm{j}$ as

$J_{w, i, j}=A\left(P_{f, i, j}-P_{p, i, j}-\pi_{f, m, i, j}+\pi_{p, m, i, j}\right)$

$J_{s, i, j}=B\left(C_{f . m, i, j}-C_{p, m, i, j}\right)$

where $\mathrm{A}$ is the membrane water permeability constant, $\mathrm{B}$ is the membrane solute permeability constant, $\mathrm{P}_{\mathrm{f}}$ is the feed pressure, and $\mathrm{P}_{\mathrm{p}}$ is the permeate pressure. $\pi_{f, m}$ is the osmotic pressure at the feed-side of the membrane interface, and $\pi_{p, m}$ is the osmotic pressure at the permeateside of the membrane interface (at the active layer), which are expressed as follows:

$\pi_{f, m, i, j}=\frac{v R T \phi_{f, m, i, j}}{M W} C_{f, m, i, j}$

$\pi_{p, m, i, j}=\frac{\nu R T \phi_{p, m, i, j}}{M W} C_{p, m, i, j}$

where $\phi_{\mathrm{f}, \mathrm{m}}$ and $\phi_{\mathrm{p}, \mathrm{m}}$ are the osmotic coefficients at the membrane interface on the feed and permeate sides, respectively. The feed-side 
concentration at the membrane interface, $\mathrm{C}_{\mathrm{f}} \mathrm{m}$, will exceed that of the bulk feed due to ECP, while the permeate-side concentration at the membrane interface, $C_{p}, m$, will be lower than that of the bulk permeate due to ICP. Note that in Eqs. (61) and (63), $\pi_{p, m}=\pi_{p}$ and $C_{p, m}=C_{p}$ for LSRRO (i.e., the osmotic pressure and bulk permeate concentration are equal to those of the permeate-side membrane interface since ICP does not occur).

$$
\begin{aligned}
& C_{f, m, i, j}=C_{f, i, j} \exp \left(\frac{J_{w, i, j}}{k_{f, i, j}}\right)-\frac{J_{s, i, j}}{J_{w, i, j}}\left(\exp \left(\frac{J_{w, i, j}}{k_{f, i, j}}\right)-1\right) \\
& C_{p, m, i, j}=C_{p, i, j} \exp \left(-J_{w, i, j}\left(\frac{S}{D}+\frac{1}{k_{p, i, j}}\right)\right)-\frac{J_{s, i, j}}{J_{w, i, j}}\left(\exp \left(-J_{w, i, j}\left(\frac{S}{D}+\frac{1}{k_{p, i, j}}\right)\right)-1\right)
\end{aligned}
$$

$\mathrm{S}$ is the structural parameter, $\mathrm{D}$ is the diffusion coefficient, and $\mathrm{k}$ is the mass transfer coefficient.

\subsubsection{Specific energy consumption}

The specific energy consumption for LSRRO can be expressed as

$$
\begin{aligned}
S E C_{L S R R O} & =\frac{1}{\eta_{p} Q_{p}}\left[(Q \Delta P)_{H P, R O}+(Q \Delta P)_{B P, R O}+\sum_{j=2}^{N_{s}}\left(Q_{j} \Delta P_{j}\right)_{H P, L S R}\right. \\
& \left.+\left(Q_{j} \Delta P_{j}\right)_{B P, L S R}\right]
\end{aligned}
$$

where LSR represents the low-salt-rejection membrane modules, the subscript, HP, denotes a high-pressure pump, BP is the booster pump, $\mathrm{Q}_{\mathrm{j}}$ represents the flowrate of the respective pump at stage $j$, and $\Delta P_{j}$ represents the pump discharge pressure minus the pump inlet pressure at stage $j$, and $Q_{p}$ final permeate flow rate. The efficiency of each pump, $\eta_{p}$, is assumed constant and thus is carried outside of the summation (see Supplementary material for converting the unit for SEC to $\mathrm{kWh} / \mathrm{m}^{3}$ ).

The specific energy consumption for COMRO can be expressed as

$$
\begin{aligned}
S E C_{\text {СОмRO }} & =\frac{1}{\eta_{p} Q_{p}} \sum_{j=1}^{N_{s}}\left(Q_{j} \Delta P_{j}\right)_{H P, B C C}+\left(Q_{j} \Delta P_{j}\right)_{B P, B C C}+\left(Q_{j} \Delta P_{j}\right)_{L P, B C C} \\
& +\left(Q_{j} \Delta P_{j}\right)_{H P, R O}+\left(Q_{j} \Delta P_{j}\right)_{B P, R O}
\end{aligned}
$$

where the subscript LP is the low-pressure feed pump that provides feedwater flow into the permeate channel of the BCC module.

The specific energy consumption for OARO can be expressed as

$$
\begin{aligned}
S E C_{O A R O} & =\frac{1}{\eta_{p} Q_{p}}\left[(Q \Delta P)_{H P, R O}+(Q \Delta P)_{B P, R O}+\sum_{j=2}^{N_{s}}\left(Q_{j} \Delta P_{j}\right)_{H P, B C C}\right. \\
& \left.+\left(Q_{j} \Delta P_{j}\right)_{B P, B C C}+\left(Q_{j} \Delta P_{j}\right)_{L P, B C C}\right]
\end{aligned}
$$

\subsubsection{Levelized cost of water}

The general equation for the LCOW is expressed as

$$
L C O W=\frac{C R F^{*} C A P E X+O P E X}{L F^{*} \sum Q_{p}}
$$

where CRF is the capital recovery factor, CAPEX is the total capital cost of the system, OPEX is the annual operation and maintenance cost, LF is the load factor (or operational availability) of the plant throughout the year, and $Q_{p}$, the design water production rate, is summated over a year.

The capital recovery factor is expressed as

$$
C R F=\frac{r}{1-\frac{1}{(1+r)^{t}}}
$$

where $r$ is the discount rate and $t$ is the plant lifetime. The capital cost of each system comprises costs for membrane modules, pumps, ERDs, and miscellaneous capital costs accounted for via a practical investment factor. The operation and maintenance costs include those for labor, maintenance, chemicals, and electricity. OARO has one additional O\&M cost component, which is the saline makeup cost, to assist with maintaining the salt balance between stages by adding saturated $\mathrm{NaCl}$ solution as new makeup to the system as needed.

\subsubsection{Technical \& cost parameters for technology comparison}

In this study, we focus on the scenario of desalinating feedwater at $70 \mathrm{~g} / \mathrm{L}$ TDS at a water recovery rate of $75 \%$, which leads to a brine concentration of about $250 \mathrm{~g} / \mathrm{L}$. We assume that $\mathrm{NaCl}$ concentration is equivalent to TDS. For the recovery rate of $75 \%$, we adopt the metric from Bartholomew et al. [11] for all optimization runs, where recovery rate is defined as the mass of water recovered from the mass of water fed into the system, as opposed to the more commonly used metric of solution recovery rate. Moreover, with exception of the water permeability and solute permeability of membranes, baseline technical (Table 1) and cost parameters (Table 2) used for the optimization models of the three technologies, were also adopted from the OARO model of Bartholomew et al. [11]; a comparison of our OARO results for LCOW and SEC with those of the aforementioned study is shown in the Supplementary material.

The permeability-selectivity tradeoff should be considered when selecting values for water permeability, A, and membrane salt permeability, B. In this study, we consider the permeability-selectivity tradeoff relationship for thin-film-composite (TFC) polyamide membranes $[33,36]$, i.e.,

$B=\gamma A^{3}$

where the empirical constant $\gamma=0.0133 \mathrm{~L}^{-2} \mathrm{~m}^{4} \mathrm{~h}^{2} \mathrm{bar}^{3}$ (corresponding to units of $\mathrm{L} / \mathrm{m}^{2} / \mathrm{h} /$ bar for $\mathrm{A}$ and $\mathrm{L} / \mathrm{m}^{2} / \mathrm{h}$ for B). For modeling the LSR membrane, we considered the typical range of monovalent solute rejection for nanofiltration membranes which is $10-90 \%[37,38]$. Thus, we expected that $\mathrm{NaCl}$ permeability coefficients for LSR membranes should be representative of the low end of this rejection range (see Supplementary material for supporting figure showing relationship of solute rejection with A/B ratio and NDP). For the baseline A value of each technology, we assume a value of $1.5 \mathrm{~L} / \mathrm{m}^{2} / \mathrm{h} / \mathrm{bar}$ (LMH/bar) since representative values for commercial SWRO membranes typically range from 1 to $2 \mathrm{LMH} /$ bar [39]. To determine the baseline B value of each technology, we ran the optimization model with $B$ as a variable, with the lower bound set by the permeability-selectivity tradeoff relationship, and thus select the resulting $B$ value associated with the cost optimal result at the given baseline conditions in Tables 1 and 2 .

The maximum pressure limit for LSR membranes in LSRRO and BCC membranes in COMRO and OARO were assumed to be 65 bar, while the limit for conventional RO membranes was set to 85 bar in each system. The baseline cost of LSR membranes was assumed to be the same as the baseline cost assumed for BCC membranes $\left(\$ 50 / \mathrm{m}^{2}\right)$. The capital recovery factor was set to $\approx 10 \%$, corresponding to a $7.8 \%$ discount rate and 20-year plant lifetime. Additionally, the following simplifications were made:

- Diffusion coefficient of $\mathrm{NaCl}$ is constant

- Osmotic coefficient relationship adopted from [11] to account for nonlinearity between osmotic pressure and concentration at high salinity

- Hydraulic diameters of feed and permeate channels assumed to be $\approx 2 \times$ the channel height

- A and B values are constant across each stage (as opposed to optimizing A and B for each stage)

- Multiple BCC modules in series within a given stage (as modeled in [24]) were not accounted for in COMRO 


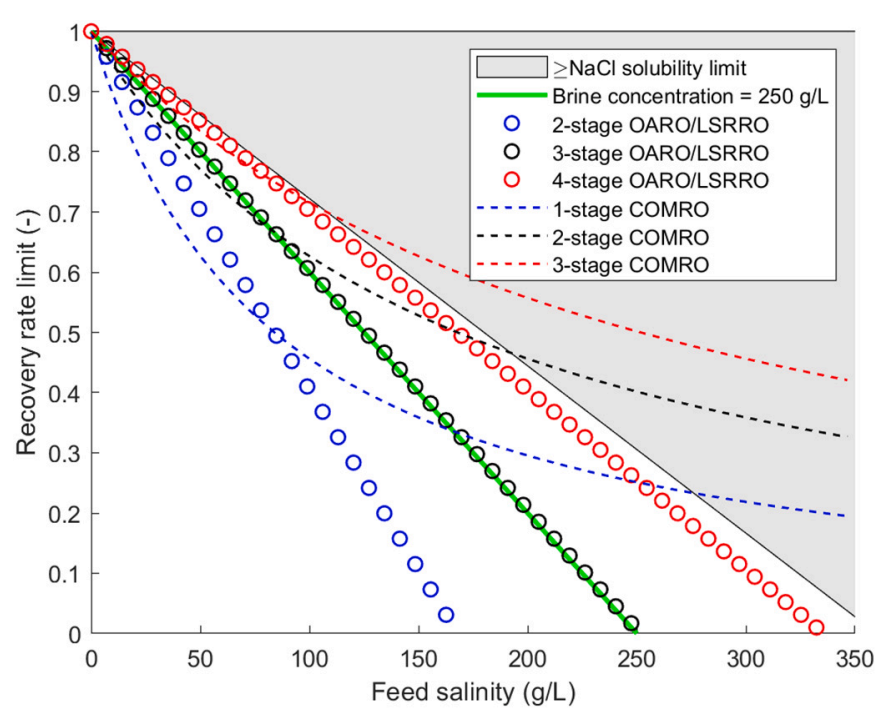

Fig. 4. Recovery rate limit as a function of feed salinity; maximum applied pressure set to $70 \mathrm{bar}$, and water temperature $=20^{\circ} \mathrm{C}$; An ideal salt rejection of $100 \%$ is assumed for the conventional RO module in LSRRO and all modules in OARO and COMRO, while salt rejection approaches 0 for the low-salt-rejection modules in LSRRO. The gray region indicates conditions where the approximate solubility limit of $\mathrm{NaCl}(\approx 360 \mathrm{~g} / \mathrm{L})$ is met or exceeded.

\section{Results and discussion}

\subsection{Recovery rate limit}

Following the ideal assumptions detailed in Section 2.3, Fig. 4 shows a comparison of theoretical recovery rate limits for COMRO, LSRRO, and OARO as a function of feed salinity, based on Eqs. (2) and (3). The recovery rate of OARO and LSRRO depend on the number of stages in the system. Although LSRRO uses LSR modules to reduce transosmotic pressure while OARO uses BCC modules to accomplish the same, LSRRO and OARO show the same linear relationship for theoretical recovery rate as a function of feed concentration. Thus, to increase the level of brine concentration, or to treat feedwaters with high initial concentrations, OARO and LSRRO would require multiple stages. Meanwhile, COMRO could recover water from high-salinity feedwater with just one stage, comprising one BCC module paired with a conventional RO module (as shown in Fig. 1). While adding BCC modules between the first BCC and the conventional RO module would reduce energy consumption [24], it would not increase the potential recovery rate; however, adding more COMRO stages (as depicted in Fig. 2) would increase the recovery rate.

For the example shown in Fig. 4, a 2-stage OARO or LSRRO system would only be able to concentrate incoming feedwater up to a concentration of approximately $160 \mathrm{~g} / \mathrm{L}$. To achieve this level of brine concentration, the LSR module in LSRRO needs to approach an observed salt rejection of $\approx 0$, while OARO requires a saline sweep on the permeate side of the BCC membrane. Comparatively, in terms of overcoming osmotic pressure, a single COMRO stage can theoretically recover water from feedwater concentrations that approach the solubility limit of $\mathrm{NaCl}$ at $\approx 360 \mathrm{~g} / \mathrm{L}$. At least 3 stages would be required by LSRRO and OARO to concentrate feedwater to a final brine concentration of $250 \mathrm{~g} / \mathrm{L}$. On the other hand, while 1-stage COMRO could not achieve this level of brine concentration for initial feedwater concentrations below $\approx 166 \mathrm{~g} / \mathrm{L}$, it could concentrate initial feed concentrations of $\geq 166 \mathrm{~g} / \mathrm{L}$ up to a final brine concentration $\geq 250 \mathrm{~g} / \mathrm{L}$ (see intersection between lines for brine concentration $=250 \mathrm{~g} / \mathrm{L}$ and 1 -stage COMRO). Adding COMRO stages would enable concentration of lower feed salinities up to $250 \mathrm{~g} / \mathrm{L}$. Thus, compared with LSRRO and OARO, COMRO appears to be advantageous with respect to theoretical recovery rate for high-salinity feeds.
However, these analytical results are based on ideal assumptions and do not consider module-scale performance and the associated cost implications.

\subsection{Optimal LCOW case results}

This section presents results obtained from the module-scale cost optimization models for the baseline scenario detailed in Section 2.4. A summary of the main design parameters and cost optimal results are provided in Table 3 (additional input parameters were specified in Tables 1 and 2).

\subsubsection{Pressure profiles}

As shown in Fig. 5, the cost optimal case of each technology corresponds to maximum inlet feed channel pressures (i.e., 65 bar for BCC and LSR membranes and 85 bar for RO membranes). This agrees with the OARO assessment by Bartholomew et al. [11]. To overcome pressure drop, feed pressure values for the permeate side in COMRO and OARO are close to 2 bar since the outlet permeate channel pressure is constrained to go no lower than atmospheric pressure. Pressure on the permeate side of LSR membranes in LSRRO is assumed constant at atmospheric pressure for all stages and thus is not shown in Fig. 5.

\subsubsection{Mass and concentration profiles}

Fig. 6 shows mass flow rates moving across the respective membrane channel, normalized by feed inlet mass flow rate for each technology (i. e., $\mathrm{m}_{\mathrm{i}, \mathrm{j}} / \mathrm{m}_{\mathrm{in}}$ ). For LSRRO, we observe that the cost optimal case results in higher mass flows in earlier stages than that of COMRO and OARO. The peak mass flow rate is found at the feed inlet of stage 2 the first low-salt rejection stage, where the mass flow rate is $3.5 \times$ the system's feedwater mass flow. Mass flow rates decrease linearly in subsequent stages. These high mass flow rates explain the comparatively high energy consumption of LSRRO. For COMRO, the peak normalized mass flow rate $(1.6 \times)$ is observed in the first stage at the permeate channel outlet of the BCC module. Notably the mass flow rates through the feed channel of each BCC stage are lower than that of the BCC's permeate channel. Mass flows decrease in subsequent changes. For OARO, normalized mass flow never exceeds 1 ; mass flows subtly decrease in subsequent stages. Moreover, unlike COMRO, mass flow rates through the feed channel of each BCC stage exceed that of the BCC's permeate channel. However, its disposal and recycle streams are an additional consideration for OARO. Since a salt imbalance occurs in OARO without any disposal or recycle streams in place, these streams are needed to achieve steady-state mass conservation. While these streams are necessary, they also provide some added flexibility to the OARO design whereas the LSRRO and COMRO configurations assessed in this study do not have such advantage.

Although mass flows do not decrease considerably in subsequent stages (except for the final RO stage), concentrations decrease quasilinearly in OARO (Fig. 7C). In comparison, concentrations in LSRRO increase quasi-linearly with every subsequent stage (Fig. 7A). Recycle streams, though not shown explicitly here, enable the dilution of sweep inlet concentrations in OARO. This is because some portion of the feed outlet flow of stage $\mathrm{j}$ will be recycled to stage $\mathrm{j}-1$. Furthermore, some of

Table 3

Summary of design parameters and cost optimal results for baseline cases.

\begin{tabular}{llccc}
\hline & & LSRRO & COMRO & OARO \\
\hline Inputs & Feed flow rate in $\left(\mathrm{m}^{3} / \mathrm{d}\right)$ & 468 & 468 & 468 \\
& Feed salinity $(\mathrm{g} / \mathrm{L})$ & 70 & 70 & 70 \\
& Water recovery rate $(\%)$ & 75 & 75 & 75 \\
Optimization & Number of stages $(-)$ & 8 & 4 & 4 \\
$\quad$ results & Membrane area $\left(1000 \mathrm{~m}^{2}\right)$ & 20.7 & 40.1 & 25.4 \\
& $\begin{array}{l}\text { Specific energy consumption } \\
\left(\mathrm{kWh} / \mathrm{m}^{3}\right)\end{array}$ & 28.9 & 12.8 & 10.3 \\
& Levelized cost of water & 6.63 & 7.90 & 5.14 \\
& $\left(\$ / \mathrm{m}^{3}\right)$ & & & \\
\hline
\end{tabular}



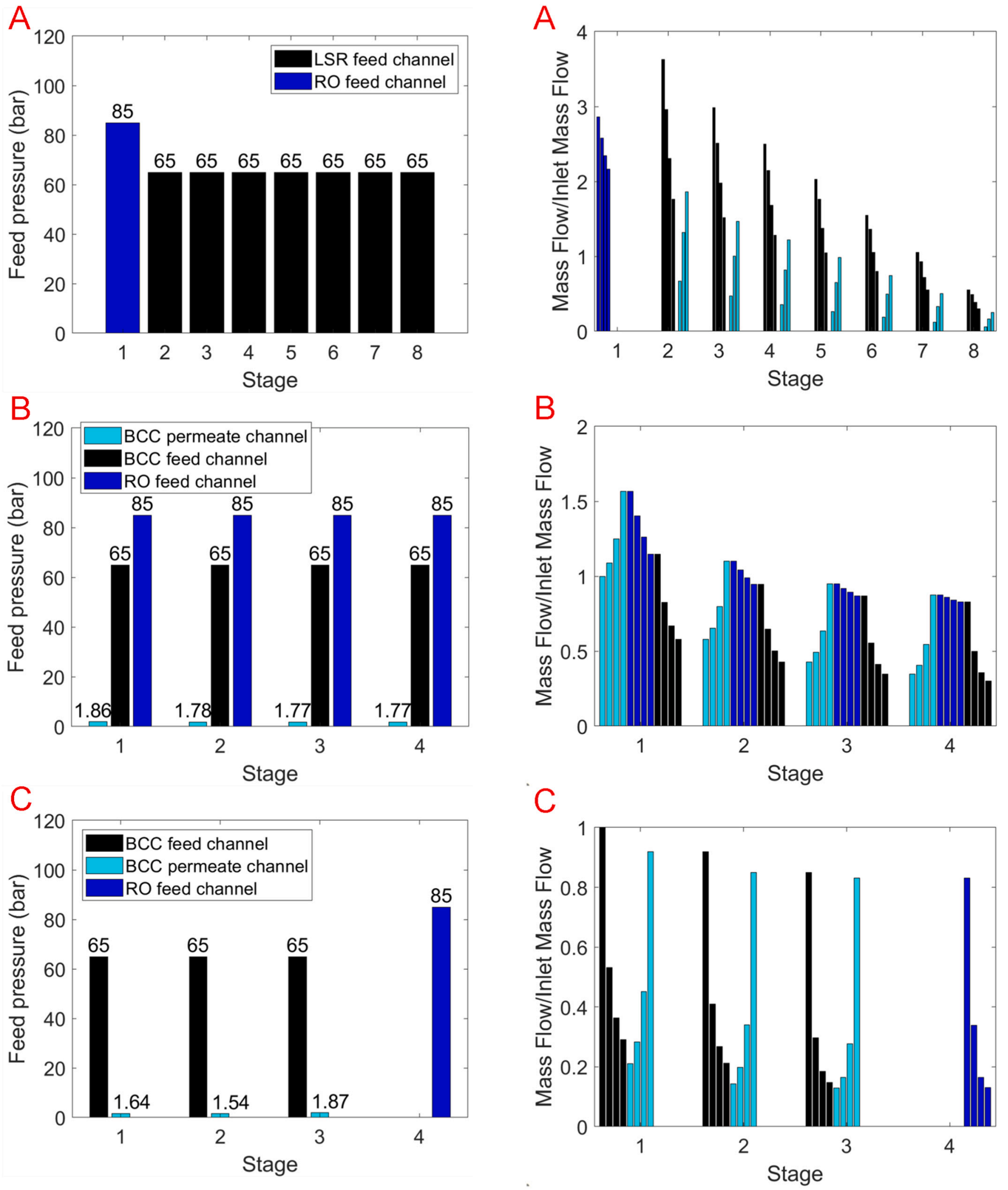

Fig. 5. Feed pressure at the inlet of each stage in LSRRO (A), COMRO (B), OARO (C) for a feed concentration and recovery rate of $70 \mathrm{~g} / \mathrm{L}$ and $75 \%$, respectively. Cyan $=$ BCC permeate channel, blue $=$ RO feed channel, black $=$ BCC/LSR feed channel (corresponding to color-coded schematics in Fig. 2).

Fig. 6. Mass flow normalized by inlet mass flow for LSRRO (A), COMRO (B), and OARO $(\mathrm{C})$. Each system has a feed concentration and water recovery rate of $70 \mathrm{~g} / \mathrm{L}$ and $75 \%$, respectively. For each stage, bars represent sections along the membrane length, starting at the respective channel inlet and ending at the outlet for each series, namely, cyan $=$ BCC/LSR permeate channel, blue $=$ RO feed channel, black $=$ BCC/LSR feed channel (corresponding to color-coded schematics in Fig. 2). 

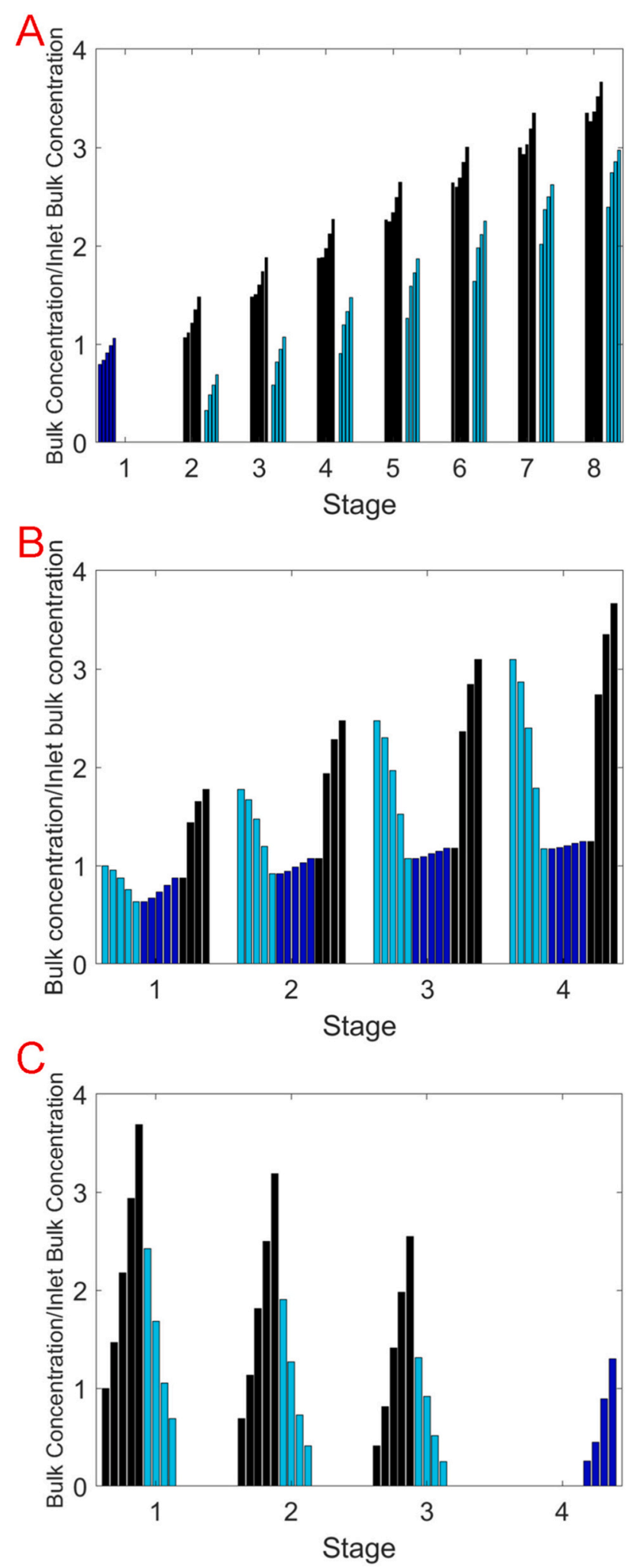

Fig. 7. Bulk concentration normalized by initial feed concentration for LSRRO (A), COMRO (B), and OARO (C). Each system has a feed concentration and water recovery rate of $70 \mathrm{~g} / \mathrm{L}$ and $75 \%$, respectively. For each stage, bars represent sections along the membrane length, starting at the respective channel inlet and ending at the outlet for each series, namely, cyan = BCC/LSR permeate channel, blue $=$ RO feed channel, black = BCC/LSR feed channel (corresponding to color-coded schematics in Fig. 2). the flow exiting the feed channel of stage 2 (which is then fed to the inlet of the permeate channel in stage 1) will be disposed of. In COMRO (Fig. 7B), feed concentration is initially diluted and then concentrated. Overall, each stage further concentrates the brine. Thus, LSRRO and COMRO concentrate the brine further with each stage while OARO fully concentrates the brine in the first stage and separates all product water in the final stage.

\subsubsection{Membrane area}

Fig. 8 shows the membrane area allocated for each stage in LSRRO, COMRO, and OARO. LSRRO requires the least total membrane area $\left(20,724 \mathrm{~m}^{2}\right)$ while COMRO requires the most $\left(40,112 \mathrm{~m}^{2}\right)$. Thus, a critical finding from these results is that COMRO requires $1.9 \times$ the membrane area of LSRRO and $1.6 \times$ that of OARO $\left(25,381 \mathrm{~m}^{2}\right)$. Regarding the membrane area allocated for conventional RO, each system has close to the same total area $\left(\approx 670 \mathrm{~m}^{2}\right)$. The discrepancy in the required membrane area is thereby attributed to the specialized modules, i.e., LSR and BCC in each system. More specifically, since COMRO must dilute incoming feedwater in each stage down to concentrations that conventional RO can handle (see concentration profile in Fig. 7), the required membrane length progressively increases from stage to stage, especially with higher inlet salinities in the last two stages. As detailed later (Section 3.2.7), this will have significant cost implications.

\subsubsection{Average permeate flux}

Fig. 9 shows the average permeate flux by stage for each technology. As expected, permeate fluxes in LSRRO are significantly higher than that of COMRO and OARO, which explains the lower requirement of membrane area. The highest average permeate flux of the LSR stages is 14.6 $\mathrm{L} / \mathrm{m}^{2} / \mathrm{h}(\mathrm{LMH})$ at the initial LSR stage and decreases to $2.54 \mathrm{LMH}$ in the last stage. For COMRO, permeate flux ranges from 0.7 to $2.3 \mathrm{LMH}$ at its BCC stages, with the highest flux occurring at the first stage and the lowest flux at the last stage. Meanwhile, permeate flux for OARO ranges from 1.1 to 3.7 LMH at its BCC stages, with the lowest flux occurring at the first stage and the highest at the last BCC stage (stage 3). While the permeate flux of the RO stages in LSRRO and OARO are approximately equal ( $\approx 21 \mathrm{LMH}$ ), COMRO's RO trains are split between each stage, where the first RO train in stage 1 has a flux of $14.3 \mathrm{LMH}$, subsequently decreasing with each stage down to a minimum of 4.2 LMH.

\subsubsection{Concentration polarization effects}

Fig. 10 shows the average concentration polarization (CP) modulus (ratio of membrane-interface concentration to bulk concentration) per stage for each technology. LSRRO only experiences ECP, and the CP modulus is highest at the conventional RO stage (first stage) with a value of 1.33. The CP modulus for LSR stages ranges from 1.00 to 1.13 , descending from stages 2 to 8 . COMRO and OARO are more heavily affected by ICP than ECP, as shown by the low CP moduli for the permeate channel in the BCC modules. OARO has values ranging from 0.46 to 0.70 , while COMRO has CP modulus values of $0.49-0.78$ in the permeate channel of the BCC modules. In terms of ECP in feed channels, the $\mathrm{CP}$ modulus of COMRO ranges from 1.03 to 1.07 in BCC modules and $1.14-1.49$ at the RO modules, while OARO ranges from 1.04 to 1.11 at the BCC modules and 1.54 at the RO stage.

The reduction of average net driving pressure because of concentration polarization is shown in Fig. 11. The non-ideal net driving pressure accounts for concentration polarization effects, while the ideal net driving pressure is based on bulk concentrations. Thus, the percent reduction of net drive pressure is computed as $100\left(1-\frac{N D P_{\text {non ideal }}}{N D P_{\text {ideal }}}\right)$. For LSRRO (Fig. 11A), ECP in the feed channel results in a 50-55\% reduction in average net driving pressure per stage. For COMRO (Fig. 11B), the combined effect of external and internal concentration polarization results in an NDP reduction of 95.3-98.8\%, increasing sequentially by stage. ECP alone accounts for a $13-18 \%$ reduction in NDP, while ICP 

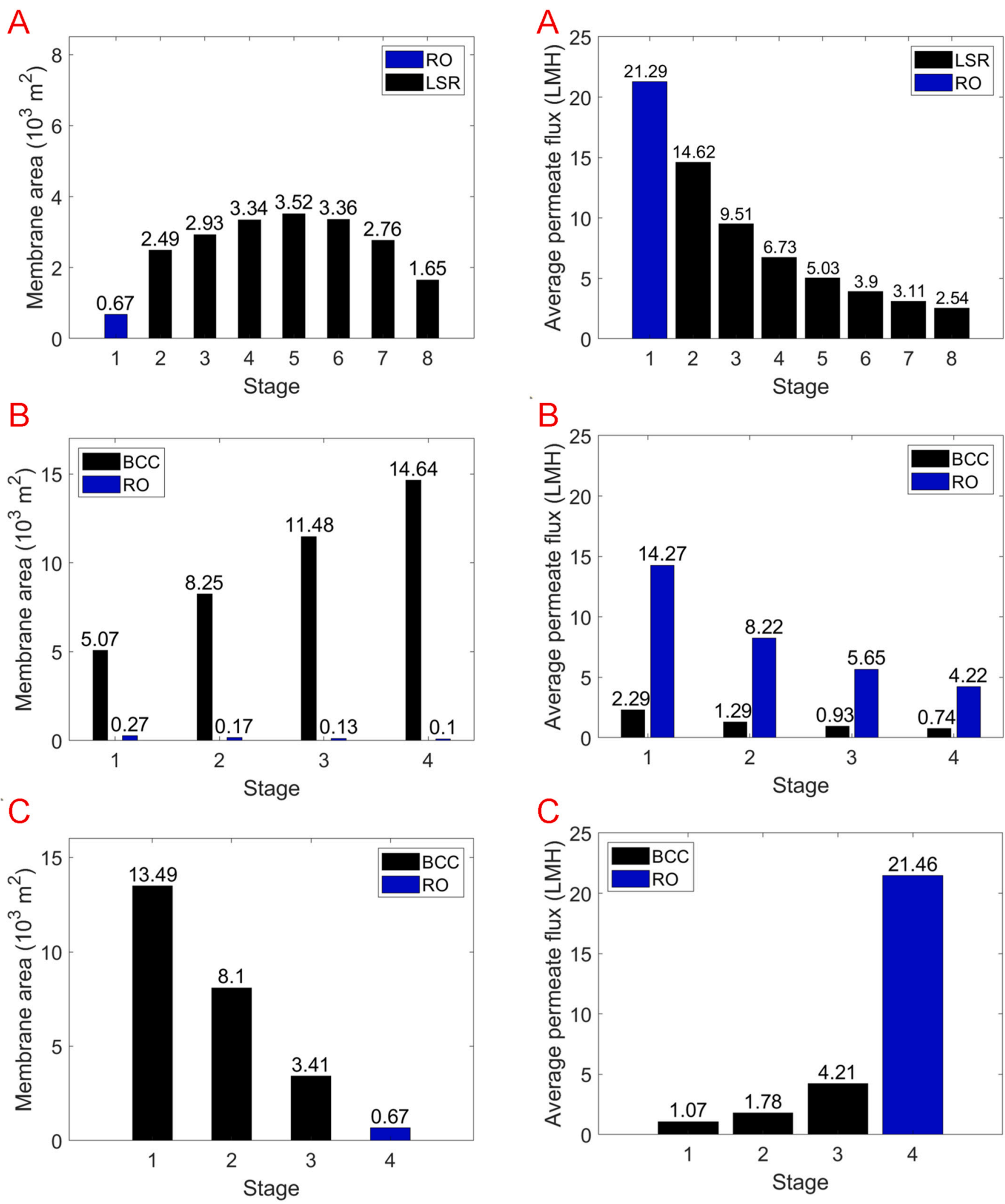

Fig. 8. Membrane area per stage in LSSRO (A), COMRO (B), and OARO (C) for a feed concentration and recovery rate of $70 \mathrm{~g} / \mathrm{L}$ and $75 \%$, respectively. Blue = RO membrane, black $=$ BCC/LSR membrane.
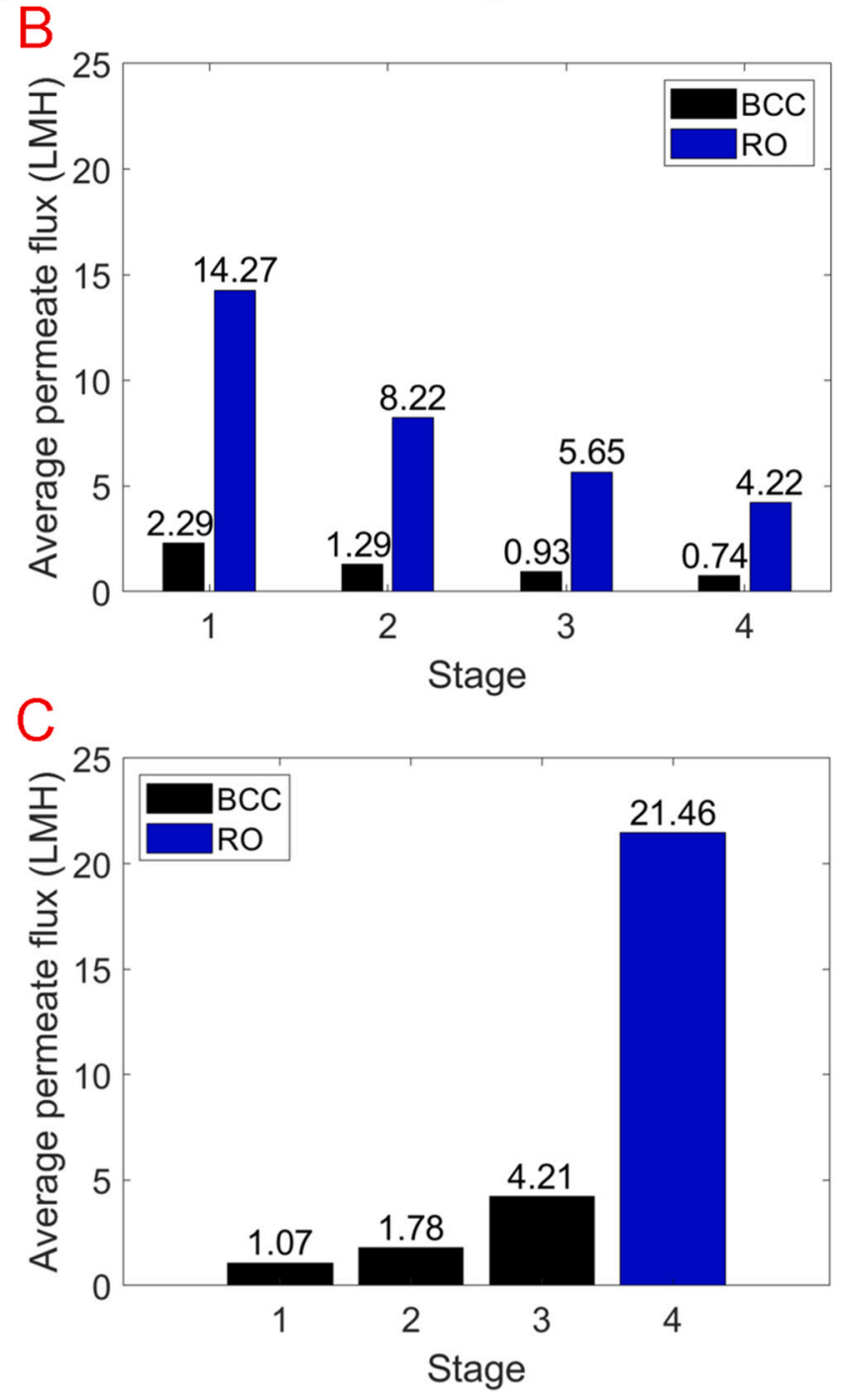

Fig. 9. Average permeate flux per stage in LSRRO (A), COMRO (B), and OARO (C) for a feed concentration and recovery rate of $70 \mathrm{~g} / \mathrm{L}$ and $75 \%$, respectively. Blue $=$ RO membrane, black $=$ BCC/LSR membrane. 


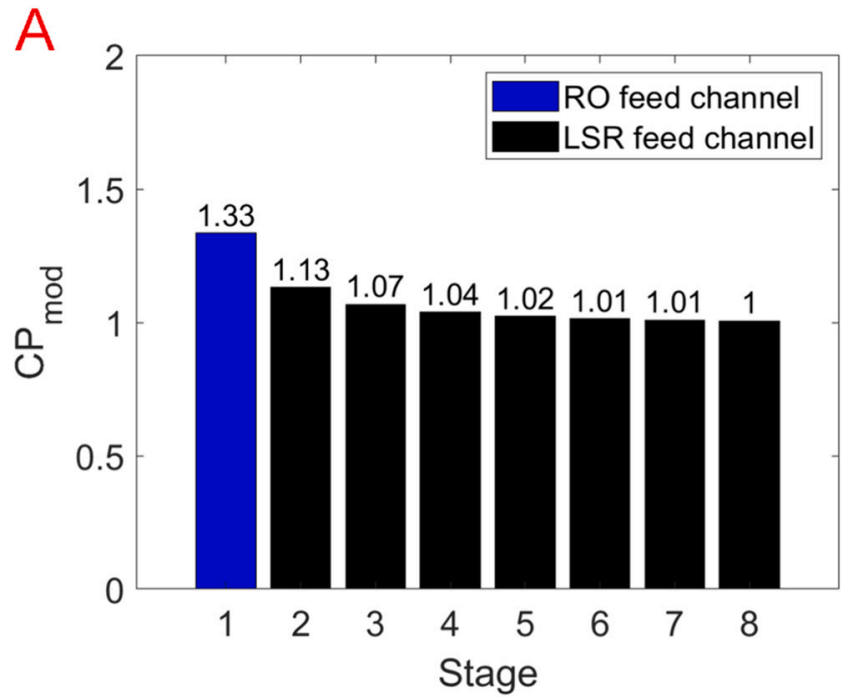

B
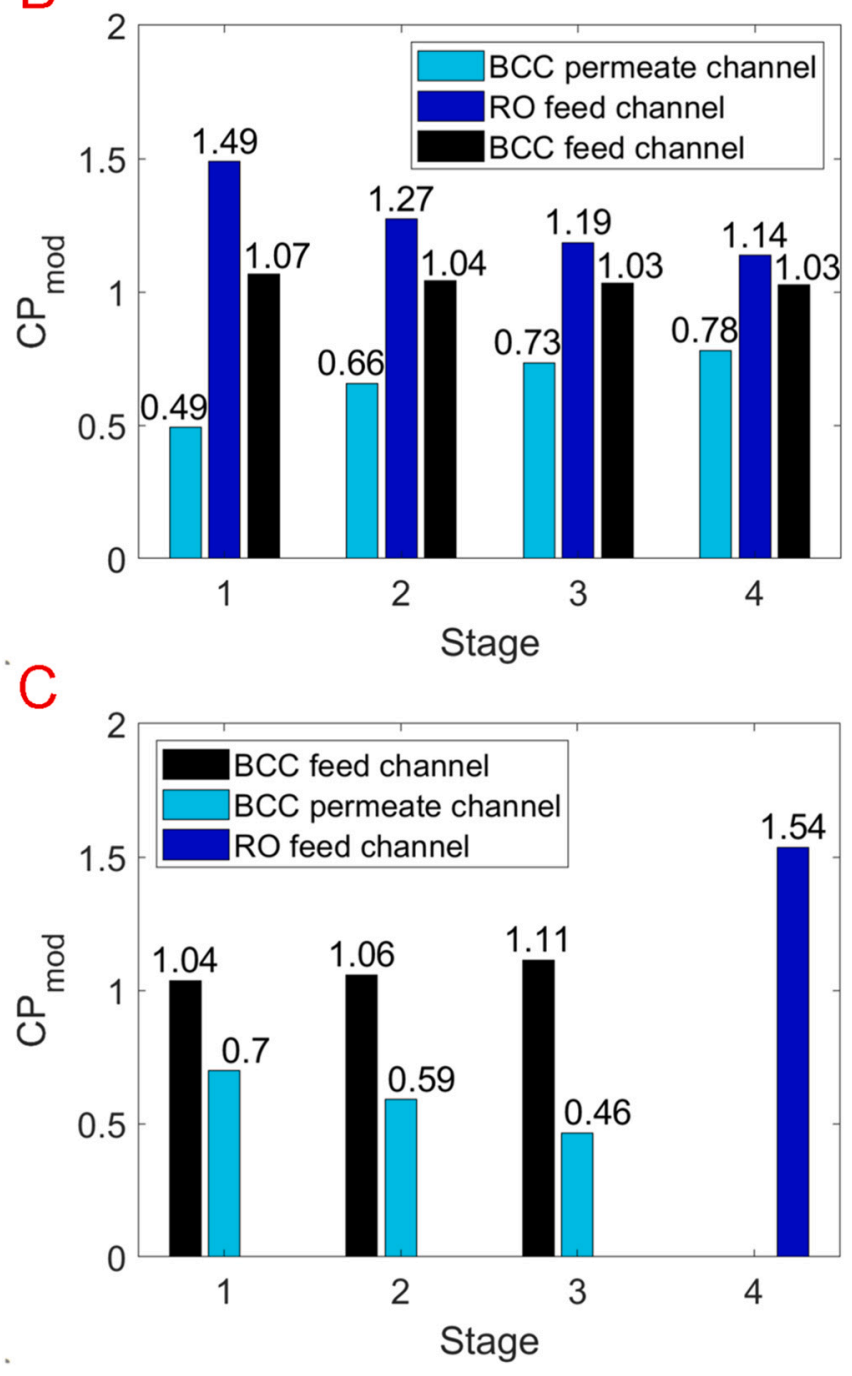

Fig. 10. Average concentration polarization modulus per stage in LSSRO (A), COMRO (B), and OARO (C) for a feed concentration and recovery rate of $70 \mathrm{~g} / \mathrm{L}$ and $75 \%$, respectively.
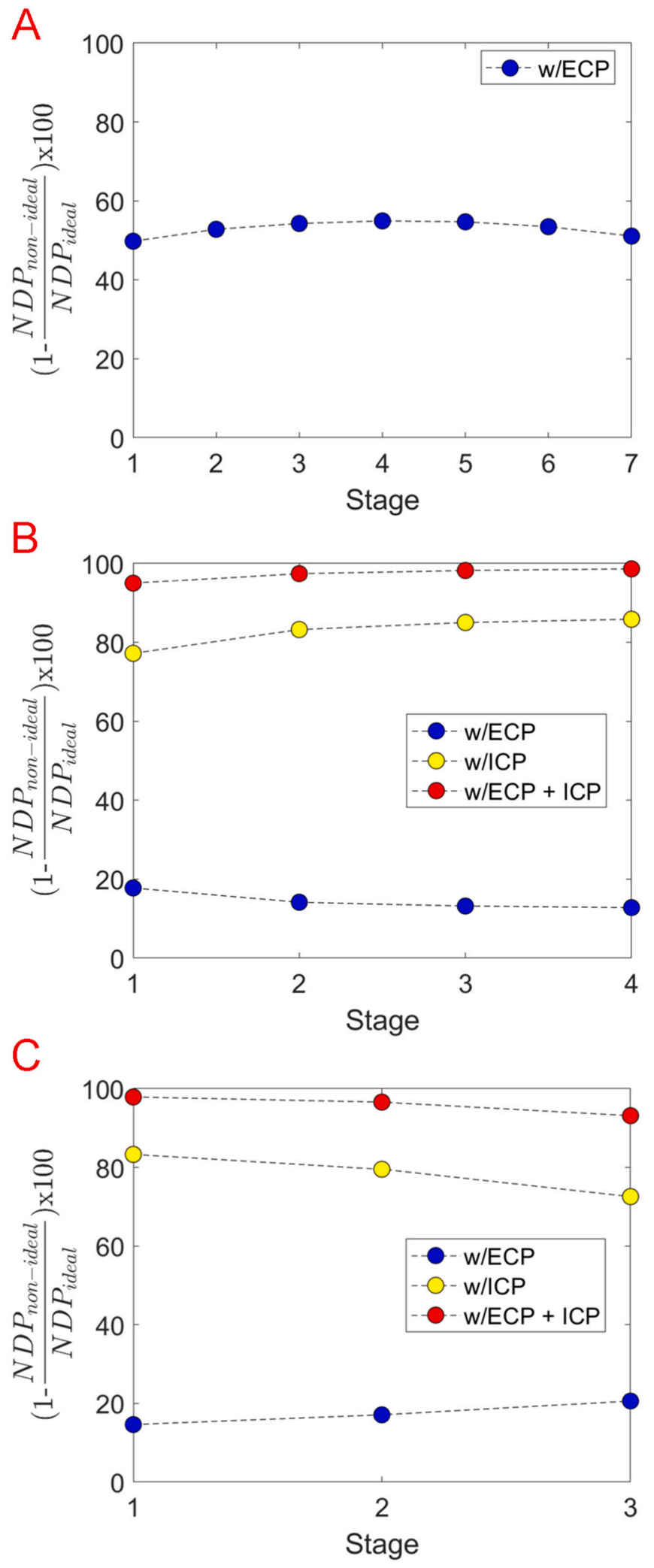

Fig. 11. Percent reduction in average net driving pressure (NDP) per stage due to concentration polarization effects for LSRRO (A), COMRO (B), and OARO (C). Results are shown only for specialized (LSR or BCC) membrane modules. $\mathrm{NDP}_{\text {ideal }}$ and $\mathrm{NDP}_{\text {non-ideal }}$ represent net driving pressure when excluding and including concentration polarization effects, respectively. The effects of external concentration polarization (ECP), internal concentration polarization (ICP), and both ECP and ICP on reducing average NDP are shown. 
alone accounts for $78-86 \%$. Thus, ICP has a more significant effect than ECP. Similarly, for OARO (Fig. 11C), ECP, ICP, and the combined effect of both results in NDP percent reductions of 14-21, 73-83, and 93.8-97.9, respectively. Although ICP also has a more significant impact than ECP in OARO, the effect of ICP on NDP reduction is less than that of COMRO. Moreover, the combined effect of ECP and ICP is slightly less
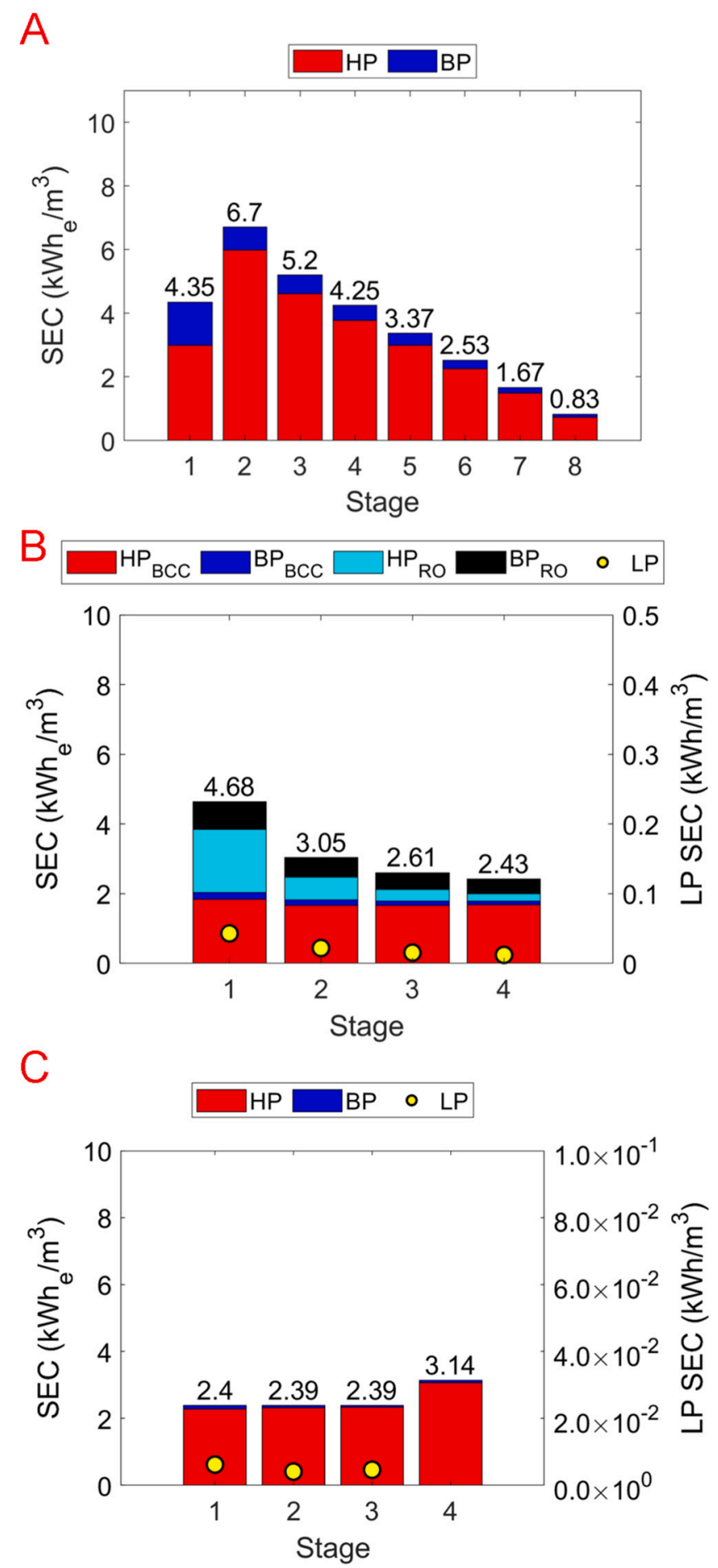

Fig. 12. Breakdown of specific energy consumption per stage in LSSRO (A), COMRO (B), and OARO (C) for a feed concentration and recovery rate of $70 \mathrm{~g} / \mathrm{L}$ and $75 \%$, respectively. Total SEC per stage is labeled over each bar. Color coding corresponds to pumps shown in Fig. 2. HP = high pressure pump, BP = booster pump, $\mathrm{LP}=$ low pressure pump, $\mathrm{BCC}=$ bilateral countercurrent, $\mathrm{LSR}=$ low-salt rejection, $\mathrm{RO}=$ reverse osmosis. severe in OARO than in COMRO.

\subsubsection{Specific energy consumption}

Fig. 12 shows the total SEC and breakdown for each stage in LSRRO, COMRO, and OARO. The total SEC for desalinating a $70 \mathrm{~g} / \mathrm{L}$ feed at $75 \%$ is $28.9,12.8$, and $10.3 \mathrm{kWh} / \mathrm{m}^{3}$ for LSRRO, COMRO, and OARO, respectively. Thus, the results show that LSRRO would have the highest energy consumption at more than double the SEC of COMRO and OARO. The increase in SEC and thus the cost of electricity consumption will be balanced out by the lower cost attributed to membranes. Moreover, the energy consumption is related to the feed pressure values (Section 3.2.1) and mass flow rates (Section 3.2.2) throughout the system. Since feed pressure for each case is set at its corresponding maximum values, this indicates that the primary discrepancy between SEC results for each technology is mainly attributed to mass flow rates. For LSRRO, the SEC peaks at the second stage $\left(6.7 \mathrm{kWh} / \mathrm{m}^{3}\right)$, where the inlet mass flow rate is highest and decreases subsequently across stages. This is attributed to high recirculation flow rates. For LSRRO and COMRO, high-pressure pumps feeding the conventional RO modules generally have a lower SEC than the high-pressure pumps that feed the LSR and BCC modules, respectively. On the other hand, for OARO, the high-pressure pump for the conventional RO stage is the highest contributor to the SEC.

\subsubsection{Levelized cost of water}

The breakdown of LCOW for LSRRO, COMRO, and OARO is presented in Fig. 13. LCOW components are segregated by the initial capital investment for membrane modules, pumps, energy recovery devices, miscellaneous capital costs, membrane replacement, electricity, and miscellaneous operation \& maintenance. Miscellaneous CAPEX accounts for other capital expenditures that are encapsulated by the assumed practical investment factor of 1.6, while miscellaneous OPEX accounts for chemical, labor, and maintenance costs.

For desalinating a feed concentration of $70 \mathrm{~g} / \mathrm{L}$ at $75 \%$ water recovery, the total LCOW for each technology is $6.63,7.90$, and $5.14 \$ / \mathrm{m}^{3}$ of water produced, respectively. COMRO has the highest cost of water, which is mainly attributed to the large amount of membrane area required (as detailed in Section 3.2.3). Meanwhile, LSRRO has the lowest membrane area requirement, but its energy cost comprises $31 \%$ of the LCOW, assuming a cost of electricity of $\$ 0.07 / \mathrm{kWh}$. For OARO and COMRO, the energy cost comprises 14 and $11 \%$ of the LCOW, respectively. In terms of membrane costs, initial capital costs for membrane modules comprise 14,22 , and $22 \%$ of the LCOW for LSRRO, COMRO, and OARO, respectively; membrane replacement costs comprise 20,33 , and $32 \%$, respectively. Thus, membrane costs are dominant for COMRO and OARO, while energy cost is dominant in the LCOW of LSRRO. Overall, OARO has the lowest cost of water due to having the lowest energy cost, lower membrane costs than COMRO, and the lowest costs for pump and ERD equipment. Translating the results to unit capital costs and considering the $90 \%$ load factor, LSRRO, COMRO, and OARO would cost $9096,13,559$, and $7717 \$ / \mathrm{m}^{3} /$ day of freshwater production, respectively (corresponding to $6688,8973,5674 \$ / \mathrm{m}^{3} /$ day of feedwater).

\subsubsection{Sensitivity analysis}

A general summary of sensitivity parameters and results are provided in Table 4.

The effect of electricity cost on the optimal LCOW (Fig. 14A) shows a linear relationship, where the slope of each line corresponds to specific energy consumption, and the intercept corresponds to the lowest LCOW that is achieved when electricity is free, for example, when excess electricity from solar and/or wind power plants that would otherwise be curtailed is used in desalination. If electricity is free, then OARO would still have a slightly lower LCOW than LSRRO although LSRRO has lower membrane area requirements. This is attributed to the pumping and ERD equipment costs that become more relevant when the energy cost of LSRRO is eliminated. As shown earlier, LSSRO requires more pumping 
10

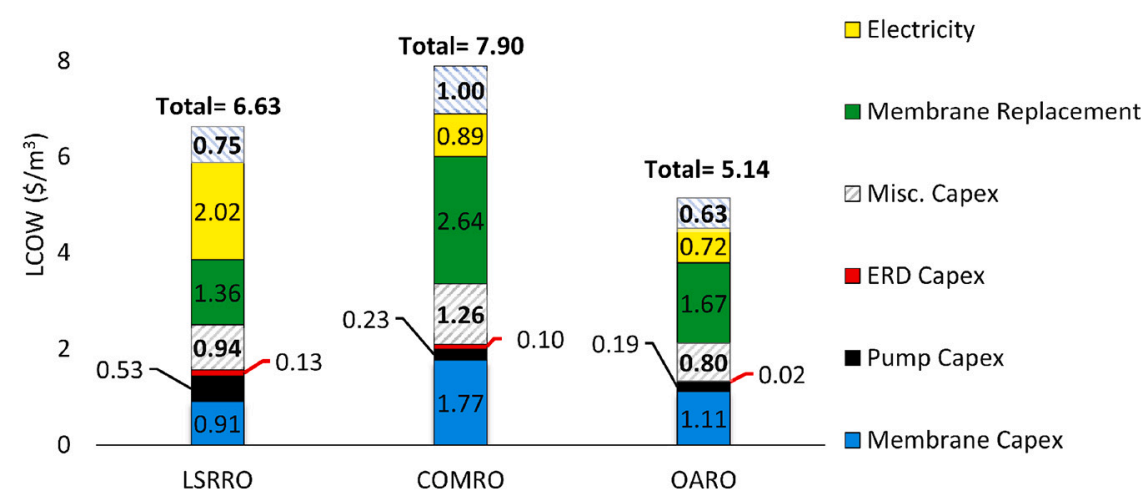

Fig. 13. Breakdown of levelized cost of water of LSRRO, COMRO, and OARO for a feed concentration and recovery rate of 70 g/L and $75 \%$, respectively.

Table 4

Summary of sensitivity results. Cool and warm colors represent decreases and increases in LCOW, respectively.

\begin{tabular}{|c|c|c|c|c|c|c|c|}
\hline \multirow[b]{2}{*}{$\mathbf{X}$} & \multirow[b]{2}{*}{ Baseline } & \multicolumn{2}{|c|}{ LSRRO } & \multicolumn{2}{|c|}{ COMRO } & \multicolumn{2}{|c|}{ OARO } \\
\hline & & $\begin{array}{l}\% \\
\text { change } \\
\text { in X }\end{array}$ & $\begin{array}{l}\text { \% change } \\
\text { in LCOW }\end{array}$ & $\begin{array}{l}\% \\
\text { change } \\
\text { in X }\end{array}$ & $\begin{array}{l}\text { \% change } \\
\text { in LCOW }\end{array}$ & $\begin{array}{l}\% \\
\text { change } \\
\text { in } X\end{array}$ & $\begin{array}{l}\text { \% change } \\
\text { in LCOW }\end{array}$ \\
\hline \multirow{2}{*}{$\begin{array}{c}\text { Electricity cost } \\
(\$ / \mathbf{k W h})\end{array}$} & 0.07 & -100.0 & -30.5 & -100.0 & -11.4 & -100.0 & -13.8 \\
\hline & 0.07 & 185.7 & 56.7 & 185.7 & 20.9 & 185.7 & 24.3 \\
\hline \multirow{2}{*}{$\begin{array}{c}\text { Membrane cost } \\
\left(\$ / \mathbf{m}^{2}\right)\end{array}$} & 50 & -40.0 & -19.2 & -40.0 & -31.7 & -40.0 & -30.6 \\
\hline & 50 & 40.0 & 19.2 & 40.0 & 31.7 & 40.0 & 28.7 \\
\hline \multirow{2}{*}{$\begin{array}{c}\text { BCC/LSR maximum } \\
\text { pressure (bar) }\end{array}$} & 65 & -23.1 & 85.5 & -23.1 & 156.9 & -23.1 & 115.2 \\
\hline & 65 & 23.1 & -29.4 & 23.1 & -33.5 & 23.1 & -31.0 \\
\hline \multirow{2}{*}{$\begin{array}{c}\text { Annual membrane } \\
\text { replacement rate } \\
(\%)\end{array}$} & 15 & -66.7 & -13.7 & -66.7 & -22.3 & -66.7 & -22.7 \\
\hline & 15 & 100.0 & 20.5 & 100.0 & 33.5 & 100.0 & 30.6 \\
\hline \multirow{2}{*}{$\begin{array}{c}\text { Structural } \\
\text { parameter (microns) }\end{array}$} & 1200 & - & - & -75.0 & -46.9 & -75.0 & -42.9 \\
\hline & 1200 & - & - & 50.0 & 29.7 & 50.0 & 29.9 \\
\hline \multirow{2}{*}{ A (LMH/bar) } & 1.5 & -76.0 & 52.3 & -76.0 & 5.9 & -76.0 & 8.3 \\
\hline & 1.5 & 33.3 & -4.4 & 33.3 & -0.1 & 33.3 & -1.5 \\
\hline
\end{tabular}

capacity than COMRO and OARO. As shown previously in Fig. 13, the capital cost component attributed to pumps and ERDs is more than 3 times higher in LSRRO than in OARO (66 cents $/ \mathrm{m}^{3}$ and 21 cents $/ \mathrm{m}^{3}$ for LSRRO and OARO, respectively). Thus, the LCOW values associated with free electricity are $4.60,7.00$, and $4.50 \$ / \mathrm{m}^{3}$, corresponding to 31,11 , and $14 \%$ lower costs than baseline values for LSRRO, COMRO, and OARO, respectively. Reducing the baseline cost of 7 cents/kWh to 3 cents/kWh results in 17,6 , and $9 \%$ reductions in LCOW for LSRRO, COMRO, and OARO, respectively; notably, utility-scale solar and windbased electricity can currently achieve a levelized cost of energy as low as $\approx 2-3$ cents/kWh [40]. On the other hand, increasing electricity cost from 7 to 20 cents/kWh would increase the LCOW by 57,21 , and $24 \%$ for LSRRO, COMRO, and OARO, respectively.

Decreasing the baseline membrane module cost of LSR and BCC modules from 50 to $\$ 30 / \mathrm{m}^{2}$ would reduce the LCOW of LSRRO, COMRO, and OARO by 19, 32, and 31\%, respectively (Fig. 14B). Meanwhile, increasing the membrane module cost of LSR and BCC modules from 50 to $\$ 70 / \mathrm{m}^{2}$ would increase the LCOW of LSRRO, COMRO, and OARO by 19,32 , and $29 \%$, respectively. In the near term, reduced membrane costs seem more likely for LSRRO than for BCC modules in COMRO and OARO because modules would be similar to low-rejection NF modules, so long as the membrane burst pressure is high enough to enable increased feed pressures.

Reducing the maximum allowable feed pressure has a significant impact on LCOW (Fig. 14C). If the maximum allowable pressure of LSR and BCC membranes is lowered from 65 to 50 bar, the LCOW increases by factors of 1.9, 2.6, and 2.2 for LSRRO, COMRO, and OARO, respectively. Of all the sensitivity analyses conducted in this study, decreasing the maximum pressure to 50 bar resulted in the highest increase of the LCOW. Although not shown, it is worth mentioning that increasing the salt permeability, B, of LSR and BCC membranes could partially remedy this; as an example, we observed that the LCOW of COMRO only increased by $2 \times$ (as opposed to 2.6) when allowing the solver to recompute $\mathrm{B}$ (the cost optimal $\mathrm{B}$ value corresponding to the baseline case of $70 \mathrm{~g} / \mathrm{L}$ feed with $75 \%$ recovery was used for all sensitivity cases, with exception of the sensitivity analysis on membrane water permeability, A.) Thus, using membranes with increased salt permeability may be beneficial when the maximum allowable pressure cannot be increased. On the other hand, increasing the maximum pressure from 65 to 80 bar would reduce the LCOW by factors of $1.4,1.5$, and 1.5 for LSRRO, COMRO, and OARO, respectively.

The baseline membrane replacement rate was set to an equivalent annual replacement rate of $15 \%$, corresponding to a membrane lifetime of 5 years at the assumed discount factor of $7.8 \%$. (All the other components of the system were assumed to have a life expectancy of 20 years.) Note that the membrane cost of $\$ 50 / \mathrm{m}^{2}$ is meant to include the module cost (i.e., with pressure vessel), and since only membrane elements would be replaced, the annual replacement rate should be a fraction of what was assumed, based on the ratio of membrane element to full module cost. Thus, this is a conservative estimate for membrane 

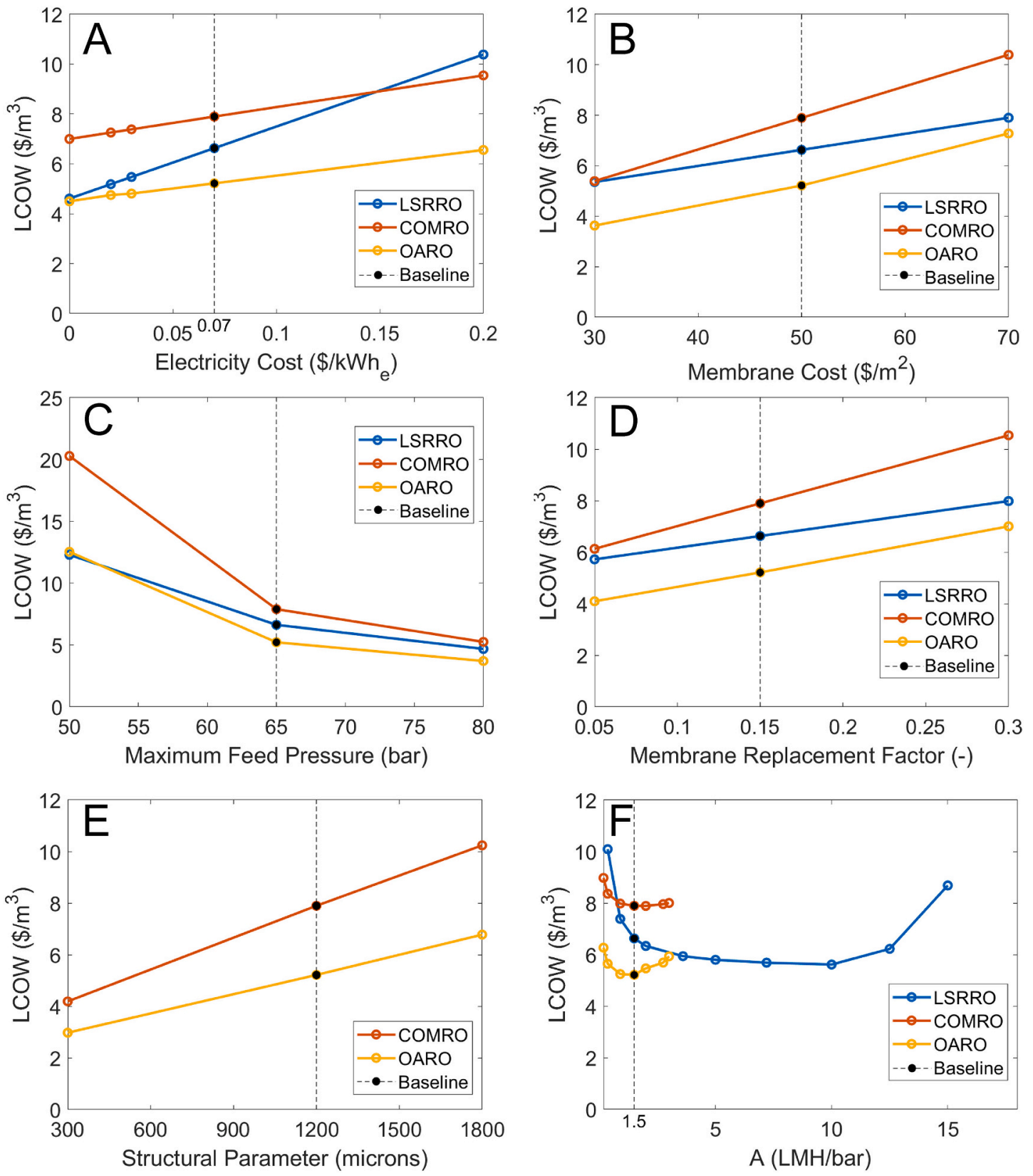

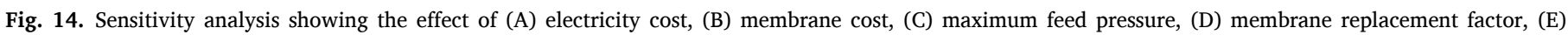

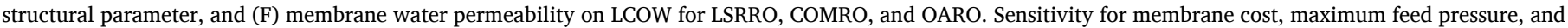

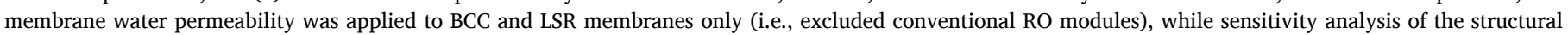
parameter was applied only for COMRO and OARO.

replacement cost. Nevertheless, as observed in the LCOW breakdown (Fig. 13), membrane replacement is the most significant cost component in COMRO and OARO. As shown in Fig. 14D, reducing the annual membrane replacement from $15 \%$ to $5 \%$ (corresponding to an optimistic 10 -year membrane lifetime) decreases the LCOW by 14,22 , and $23 \%$, while increasing the replacement rate to $30 \%$ (1-year lifetime) raises the LCOW by 20,33, and 31\% for LSRRO, COMRO, and OARO, respectively. The typical lifetime of a membrane ranges from 3 to 5 years for conventional desalination [41]; without improved mitigation strategies for scaling and fouling, it is reasonable to hypothesize that membrane lifetime would be significantly shorter for such high-salinity applications.

Perhaps the most significant reduction on LCOW for OARO and COMRO is due to the structural parameter, S (Fig. 14E). Consequently, reducing the $S$ value would decrease the effects of ICP and ultimately lower the LCOW. More specifically, reducing the $S$ value would reduce the membrane area requirement, which is critical most especially for rendering multi-stage COMRO (as modeled here) as cost-competitive with OARO and LSRRO at high feed concentrations. Decreasing the $\mathrm{S}$ value from its baseline value of $1200 \mu \mathrm{m}$ down to $300 \mu \mathrm{m}$ (slightly above values recently achieved experimentally by Kwon et al. (2021) [42]) would result in a $47 \%$ decrease in LCOW, down to $\$ 4.19 / \mathrm{m}^{3}$ for COMRO; furthermore, the required membrane area decreases by $58 \%$. For OARO, lowering the $S$ value to $300 \mu$ m yields a $43 \%$ decrease in $\mathrm{LCOW}$, down to $\$ 2.98 / \mathrm{m}^{3}$, and a $55 \%$ decrease in membrane area. Increasing the $S$ value from 1200 to $1800 \mu \mathrm{m}$ would result in a $30 \%$ increase in LCOW for both COMRO and OARO.

The sensitivity analysis for A, the membrane water permeability constant, of LSR and BCC membranes (i.e., excluding conventional RO membranes in each system) is shown in Fig. 14F. In almost all cases, 
OARO achieves the lowest LCOW. COMRO achieves a lower LCOW than LSRRO when $\mathrm{A}$ is at the low end of the range (0.36 LMH/bar). Comparatively, COMRO and OARO have the same range of A values, i.e., up to $3 \mathrm{LMH} / \mathrm{bar}$, while the range of A values for LSRRO extends to 15 LMH/bar, the upper limit for commercial nanofiltration membranes $[43,44]$. This difference is attributed to the cost-optimal salt permeability constant, B, associated with each A value (Fig. 15, bottom row). Since LSRRO benefits from high B values, the A-B tradeoff limit of polyamide is not reached until $10 \mathrm{LMH} / \mathrm{bar}$. Meanwhile, COMRO and OARO favor low B values that approach the A-B tradeoff limit and are thus confined to a lower range of A values than that of LSRRO. The top row of Fig. 15 shows a magnified view of the effect of A on LCOW.

The general trends show that there is an optimum A around 1.5-2 $\mathrm{LMH}$ /bar for COMRO and OARO and $10 \mathrm{LMH}$ /bar for LSRRO. Moreover, the highest LCOWs correspond to the lowest A values. Decreasing A from 1.5 LMH/bar (value used in baseline scenarios) to $0.36 \mathrm{LMH} /$ bar for LSRRO and 0.18 LMH/bar for COMRO and OARO corresponds to an increase in LCOW by factors of 1.5, 1.1, and 1.2 for LSRRO, COMRO, and OARO, respectively. This increase in cost is primarily attributed to the required increase in membrane area (Fig. 15, third row). LSRRO is impacted the most by such a decrease in A. Decreasing A from 1.5 LMH/ bar to $0.36 \mathrm{LMH} / \mathrm{bar}$ results in double the membrane area. Meanwhile, decreasing A from 1.5 LMH/bar to $0.18 \mathrm{LMH} /$ bar corresponds to $18 \%$ and $28 \%$ increases in membrane area for COMRO and OARO, respectively. On the other hand, increasing the A value past the optimum also increases the LCOW of each technology, which can be attributed in part to the associated increase in SEC (Fig. 15, second row). Additionally, the B value increases with A according to the A-B tradeoff (Fig. 15, bottom
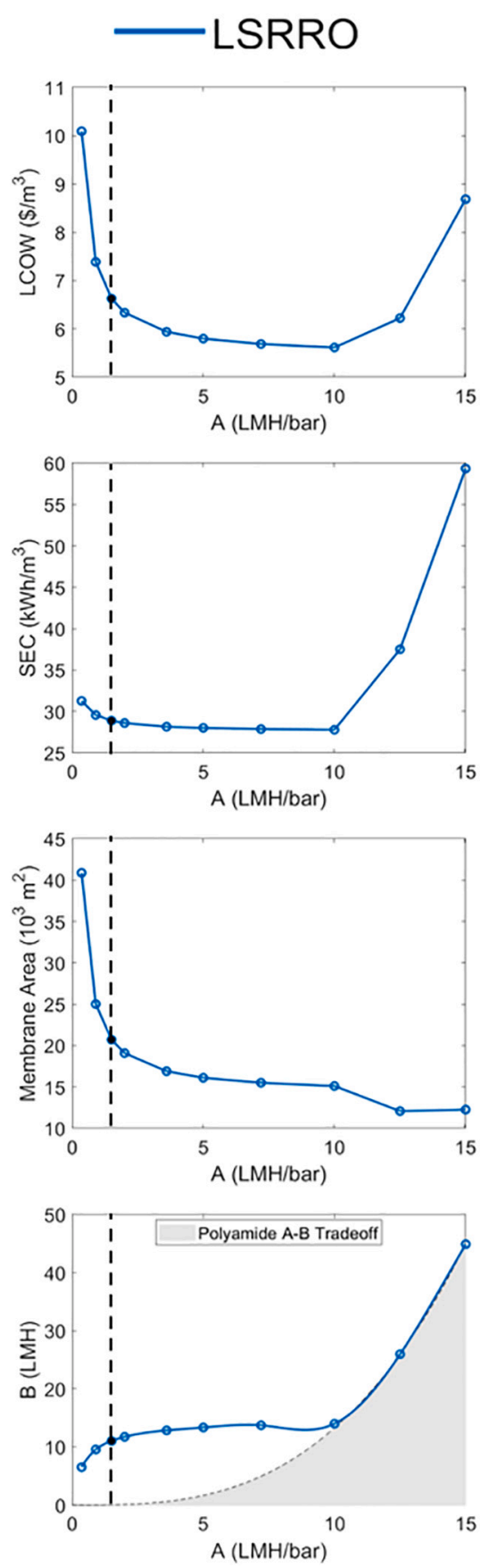

COMRO
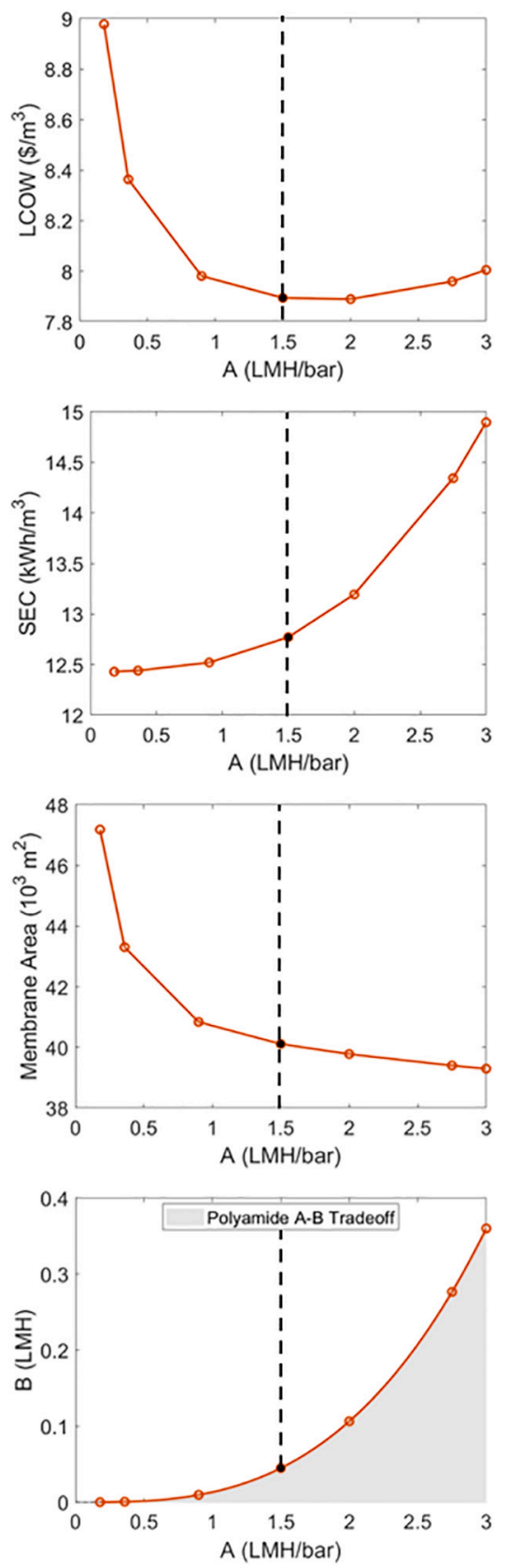
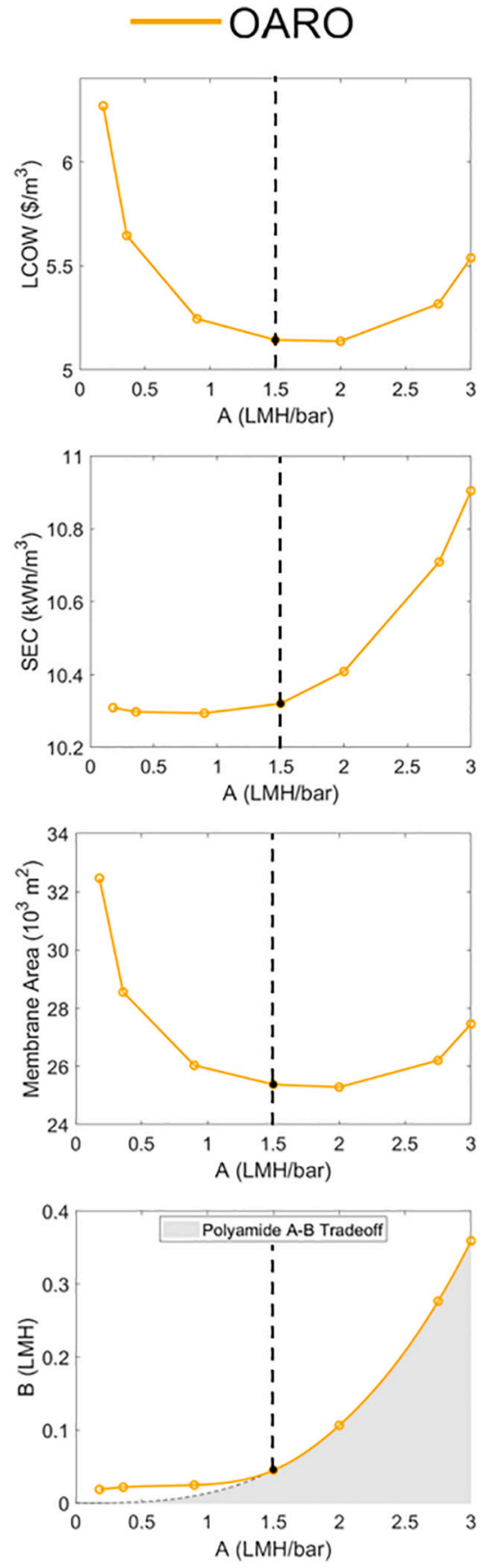

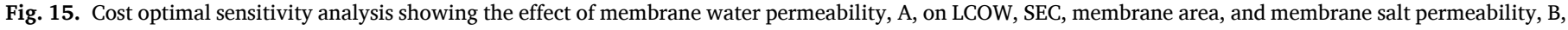
for LSRRO, COMRO, and OARO. Black point in each plot represents the baseline scenario. 
row). LSRRO experiences the most significant increase in SEC, going from 27.8 to $59.3 \mathrm{kWh} / \mathrm{m}^{3}$ when increasing A from $10 \mathrm{LMH} /$ bar to 15 $\mathrm{LMH} /$ bar, corresponding to a $31 \%$ increase in LCOW; additionally, specific capital costs for pumping are more than doubled. In terms of the impact on membrane area, increasing A above the optimum corresponds to a decrease in membrane area for LSRRO and COMRO. However, for OARO, the associated increase in LCOW at high A values is related to subtle increases in membrane area and SEC.

Fig. 16 shows the effect of feed concentration and recovery rate on LCOW (Fig. 16, top), SEC (Fig. 16, center), and number of stages (Fig. 16, bottom). While the LCOW ranged from 5.14 to $7.90 \$ / \mathrm{m}^{3}$ for desalinating a $70 \mathrm{~g} / \mathrm{L}$ feed to brine concentrations just above $250 \mathrm{~g} / \mathrm{L}$, LCOW values ranging from 1.04 to $2.53 \$ / \mathrm{m}^{3}$ to desalinate initial feed concentrations of 20 and $35 \mathrm{~g} / \mathrm{L}$ to brine concentrations above $215 \mathrm{~g} / \mathrm{L}$; LCOW values range from 0.48 to $1.02 \$ / \mathrm{m}^{3}$ when desalinating 20 and $35 \mathrm{~g} / \mathrm{L}$ to concentrations of $\approx 130 \mathrm{~g} / \mathrm{L}$. Thus, while these enhanced RO technologies can treat high initial feed concentrations (i.e., $\geq 70 \mathrm{~g} / \mathrm{L}$ ), starting at lower initial feed concentrations would certainly be more viable. The main cost drivers are membrane modules (initial investment and replacement costs) and energy costs. At lower feed and final brine concentrations, membrane and energy costs are comparable to one another in COMRO and OARO. In LSRRO, energy costs dominate over membrane costs. However, when transitioning to high feed or final brine concentrations, the difference between membrane and energy costs

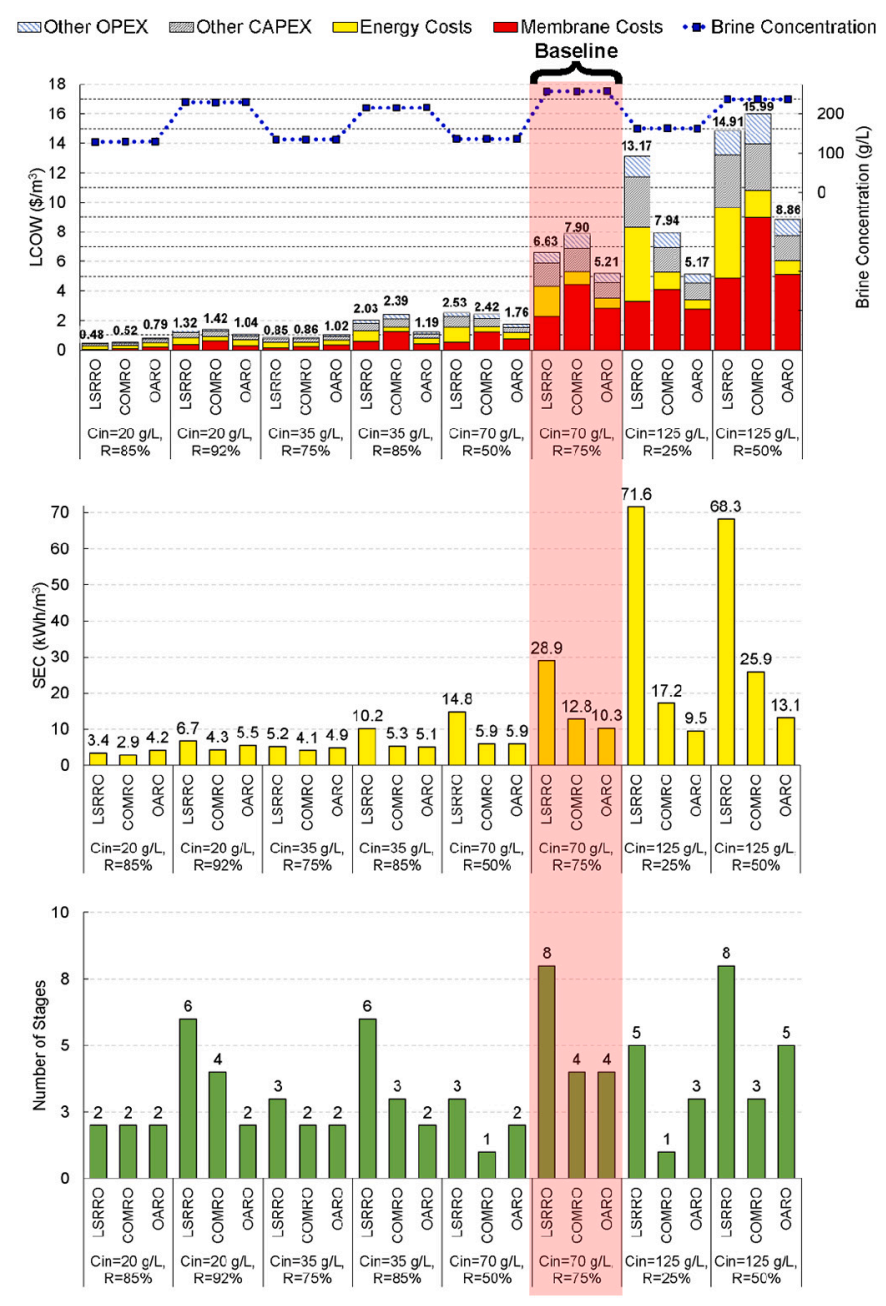

Fig. 16. The effect of feed concentration and recovery rate on cost optimal LCOW (top), SEC (center), and number of stages (bottom) for LSRRO, COMRO, and OARO. The final brine concentration for each case is also shown (top, blue squares). Membrane costs account for initial investment and replacement. Baseline cases are highlighted by the red shaded box $\left(C_{\text {in }}=70 \mathrm{~g} / \mathrm{L}, \mathrm{R}=75 \%\right)$. become more pronounced for OARO and COMRO (i.e., membrane costs become the dominant cost component), but more significantly for COMRO; on the other hand, as the membrane cost component becomes more significant, energy and membrane costs become comparable for LSRRO. Of the three technologies, OARO has the general cost advantage and is better suited for high-salinity feeds than COMRO and LSRRO. The disadvantage of LSRRO is its high SEC, reaching as high as 68.3-71.6 $\mathrm{kWh} / \mathrm{m}^{3}$ at an initial feed concentration of $125 \mathrm{~g} / \mathrm{L}$. The reason for this is related to the high recirculation flow rate required to dilute the feed that enters the conventional RO train, as observed in Figs. 6 and 12 for the baseline scenario. When increasing the initial feed concentration, this effect will be amplified. Meanwhile, at an initial feed concentration of $125 \mathrm{~g} / \mathrm{L}$, SEC ranges are $17.2-25.9$ and $9.5-13.1 \mathrm{kWh} / \mathrm{m}^{3}$ for COMRO and OARO, respectively, which are significantly lower than that of LSRRO. For COMRO, its disadvantage is its high membrane area requirement which increases with feed concentration and final brine concentration. More membrane area is needed to dilute the feed to acceptable concentrations for conventional RO (i.e., within pressure limitations). This effect is apparent when observing the allocated membrane area per stage (see Fig. 8) which shows that most of the required area is due to the last two stages where the stage inlet concentrations are quite high $(\approx 170$ and $215 \mathrm{~g} / \mathrm{L}$ for stages 3 and 4 , respectively). Overall, of the three technologies, OARO benefits from a balance of relatively low membrane area and SEC.

\subsubsection{Implications of system comparisons}

Reducing the structural parameter would be key for decreasing the effect of ICP and, in turn, reducing the membrane area to enable significant reductions in the cost of water for COMRO and OARO, but the challenge lies in the tradeoff between the structural parameter and the mechanical integrity of a membrane (i.e., there is a need for membranes with a low structural parameter and high mechanical integrity). The $S$ value of $1200 \mu \mathrm{m}$ used in our baseline analysis is fairly high and was originally meant to be representative of (and as adopted from [11], is double that of) a cellulose triacetate (CTA) membrane with a woven fabric support [45]. Recent developments have led to an S value as low as $235 \mu \mathrm{m}$ for a polyamide, polyethylene thin-film composite membrane with increased mechanical integrity as well as high water permeability [42]; these membranes outperformed commercial TFC and CTA membranes in terms of mechanical integrity and were tested for pressure retarded osmosis (PRO) operation at pressures up to 23 bar. In other work, TFC membranes with $\mathrm{A}=2.49 \mathrm{LMH} /$ bar and $\mathrm{S}=564 \mu \mathrm{m}$ were successfully operated at 48.3 bar but failed at 55.2 bar, indicating that the burst pressure lies within this range [46]. Ensuring that BCC membranes can withstand high pressures (e.g., $>50$ bar) to avoid membrane rupture will be important for reducing the LCOW, assuming such membranes would not weigh significantly on membrane cost. LSR membranes would also need to withstand such high pressures to reduce LCOW but is not expected to be as challenging as for BCC membranes. As mechanical integrity is reduced, there is more of a need for dense spacers, which would then contribute to parasitic energy losses via pressure drop in the permeate channel for COMRO and OARO [23]. While this is certainly a factor to consider, our results showed that LSRRO would have more than double the energy requirement of COMRO or OARO (in the baseline scenario). Nevertheless, although our results indicate that the difference in SEC between COMRO/OARO and LSRRO is significant, further research would be required to quantify parasitic losses in the permeate channel of BCC modules since pressure loss calculations used here do not capture this effect; i.e., new experimental data and friction factor correlations for the permeate channel in BCC modules are needed. Furthermore, membranes used for BCC modules in COMRO and OARO will likely require further development to be deployed widely at commercial scale. In LSRRO, the rate of salt passage is purposely high to render the process successful, and water permeability would also be high due to the permeability-selectivity tradeoff $[43,33,47,48]$. Thus, commercial nanofiltration membranes with low 
monovalent solute rejection may already be sufficient for initiating LSRRO as a solution for minimal liquid discharge desalination, though starting at high initial feed concentrations (e.g., $125 \mathrm{~g} / \mathrm{L}$ ) would be especially energy intensive.

Regarding the specific energy consumption and capital costs for pumping and ERD equipment, configurations in this analysis were considered fixed, with a combination of a high-pressure pumpset, a booster pumpset, and an isobaric ERD train allocated per module train. ERDs were modeled to fully depressurize brine streams down to atmospheric pressure. Alternative configurations could be considered, e.g., where ERDs partially depressurize brine streams and only a booster pump drives the subsequent stage, which could be the case in COMRO. OARO requires near-complete depressurization of brine streams to continue as low-pressure, sweep inlet streams. Nevertheless, it is reasonable to assume that pump and ERD configurations could be improved in the field to reduce associated costs or energy losses.

Multi-stage COMRO, as modeled in this study, was found to be the costliest solution when desalinating a $70 \mathrm{~g} / \mathrm{L}$ feed at $75 \%$ recovery; the primary discrepancy is because the system requires more membrane area than the other two technologies, making it more capital-intensive and requiring high membrane replacement costs. However, COMRO offers a major advantage of adding BCC modules in series to reduce the specific energy consumption [24], the effect of which was not accounted for in this analysis; potential energy savings up to $17 \%$ and $33 \%$ for 70 $\mathrm{g} / \mathrm{L}$ and $35 \mathrm{~g} / \mathrm{L}$ at $50 \%$ and $70 \%$ recovery, respectively, were reported though without directly considering non-idealities such as salt flux and concentration polarization. Nevertheless, considering the baseline assumptions and results of this analysis, even if the costs attributed to electricity, pumps, and ERDS were completely omitted, the LCOW of COMRO would approach that of LSRRO but would still exceed that of OARO. Thus, our findings indicate that modifications would have to be made to the multi-stage COMRO configuration to reduce the required membrane area and render it cost-competitive with OARO and LSRRO. One such modification includes reduction of the membrane's structural parameter. Perhaps one pathway could be to reduce the structural parameter and add BCC modules in series to reduce energy consumption. On the other hand, COMRO has one distinguishing characteristic from OARO and LSRRO, as illustrated earlier in Section 3.1 (Fig. 4) and shown further in Fig. 17: COMRO can treat high-salinity feeds even with one stage (though at considerably low overall recovery rates at high salinity), while LSRRO and OARO require multiple stages to achieve any recovery from high-salinity feeds.

The implication of this characteristic is that COMRO could be designed as a single-stage semi-batch or full batch system. Either approach could lead to a reduction in equipment (e.g., pumps, ERDs), associated costs, and specific energy consumption [49,50]. Alternatively, such a configuration could use an active-salinity-control process [51], which could facilitate system flexibility in terms of energy consumption and enable adaptation to variable power and electricity prices, ultimately meeting a vision of desalination plants that provide energy services to enable a clean electricity grid [52]. Such modifications should be explored for OARO and LSRRO as well, but COMRO seems immediately suited for such adaptations.

Lastly, scaling and fouling is already a challenge for membranebased desalination when considering brackish or seawater as the feed. Such challenges are expected to be amplified when treating high-salinity waters at high recovery rate, and the feasibility of enhanced RO would hinge upon mitigation strategies for scaling and fouling.

\section{Conclusions}

Enhanced RO has the capability of circumventing the maximum pressure limitations of conventional RO to treat hypersaline brines and increase recovery rates. Based on our results for desalinating a $70 \mathrm{~g} / \mathrm{L}$ feed concentration at 75\% recovery, comparing LSRRO, COMRO, and OARO under a common set of baseline assumptions showed that

- OARO achieved the lowest LCOW of $\$ 5.14 / \mathrm{m}^{3}$. The LCOW values for LSRRO and COMRO were 6.63 and $7.90 \$ / \mathrm{m}^{3}$, respectively.

- LSRRO has the highest SEC, with values of 28.90, 12.77, and 10.31 $\mathrm{kWh} / \mathrm{m}^{3}$ for LSRRO, COMRO, and OARO, respectively.

- Membrane costs weighed more heavily than energy costs for OARO and COMRO. Membrane replacement costs are dominant, followed by the initial investment for membrane modules, and then energy costs. For LSRRO, the reverse is true; energy is the highest contributor to the LCOW, followed by membrane replacement and initial capital for membrane modules.

Based on our results and baseline assumptions, a multi-stage COMRO system would not be cost-competitive with OARO nor LSRRO for desalinating a $70 \mathrm{~g} / \mathrm{L}$ feed and concentrating to a final brine concentration of $250 \mathrm{~g} / \mathrm{L}$. The cost discrepancy of COMRO in comparison with OARO and LSRRO diminishes at low feed concentrations (e.g., 20-35 g/L), but the disparity in LCOW between COMRO and OARO becomes more pronounced at feed concentrations at and above $70 \mathrm{~g} / \mathrm{L}$. Modifying the multi-stage COMRO configuration to reduce membrane area would be

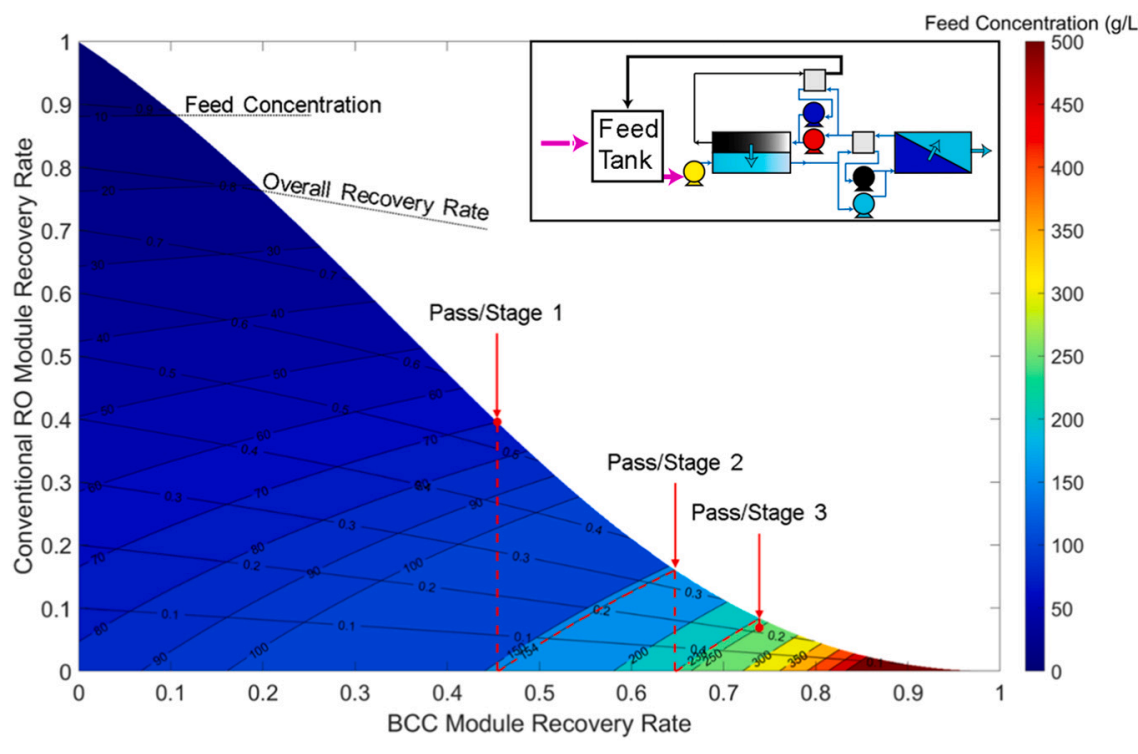

Fig. 17. Example showing multi-stage or semi-batch/ batch COMRO starting at $70 \mathrm{~g} / \mathrm{L}$ feed and concentrating to $250 \mathrm{~g} / \mathrm{L}$. Conventional RO module recovery rate versus BCC module recovery rate is shown as a function of feed concentration and overall recovery rate, based on the theoretical equations listed in Section 2.3. The inset image provides an example schematic of semi-batch/batch COMRO. Color map and corresponding contours denote feed concentration, and second set of contours indicates overall recovery rate. Maximum pressure is set to $70 \mathrm{bar}$ (corresponding to concentration of $\approx 84 \mathrm{~g} / \mathrm{L}$ TDS at the outlet of the conventional RO module), and fluid temperature is set to $20^{\circ} \mathrm{C}$. 
key to altering this outcome; from our sensitivity analyses, reducing the structural parameter had the most significant effect on reducing membrane area. Furthermore, future work should explore cases where the energy cost component would dominate over membrane costs to implement the energy reduction potential of COMRO (i.e., by adding BCC modules in series which was not accounted for in this study). Additionally, other modified configurations such as semi-batch, batch or COMRO with active-salinity control could increase viability and facilitate resilient desalination and should be explored further. Lastly, benchscale and pilot-scale experimentation is needed to comparatively assess LSRRO, COMRO, and OARO.

\section{Nomenclature}

A membrane water permeability (LMH/bar or $\mathrm{m}^{3} / \mathrm{m}^{2} / \mathrm{s} / \mathrm{bar}$ )

$A_{c} \quad$ cross sectional channel area $\left(\mathrm{m}^{2}\right)$

$A_{m} \quad$ membrane area $\left(\mathrm{m}^{2}\right)$

$B \quad$ membrane solute permeability (LMH or $\mathrm{m}^{3} / \mathrm{m}^{2} / \mathrm{s}$ )

$B C C$ bilateral countercurrent

$B P \quad$ booster pump

C concentration $(\mathrm{g} / \mathrm{L})$

$C_{b, \max }$ maximum brine concentration $(\mathrm{g} / \mathrm{L})$

CAPEX capital expenditures (\$)

CTA cellulose triacetate

CRF capital recovery factor (-)

COMRO cascading osmotically mediated reverse osmosis

$d_{h} \quad$ hydraulic diameter (m)

$\Delta P_{\max } \quad$ maximum applied pressure (bar)

$\varepsilon_{s p} \quad$ spacer porosity (-)

$\eta_{p} \quad$ pump efficiency

$F \quad$ friction factor $(-)$

$f \quad$ feed channel

$h \quad$ channel height (m)

HP high pressure pump

$i \quad$ node (or inter-node)

in inlet

j stage

$J_{S} \quad$ solute flux $\left(\mathrm{kg} / \mathrm{m}^{2} / \mathrm{s}\right)$

$J_{w} \quad$ water flux $\left(\mathrm{m}^{3} / \mathrm{m}^{2} / \mathrm{s}\right)$

$k$ mass transfer coefficient $(\mathrm{m} / \mathrm{s})$

LCOW levelized cost of water $\left(\$ / \mathrm{m}^{3}\right)$

$L F \quad$ load factor $(-)$

LMH $\quad \mathrm{L} \mathrm{m}^{-2} \mathrm{~h}^{-1}$

$L P \quad$ low pressure pump

$L S R R O$ low salt rejection reverse osmosis

LSR low salt rejection

$\mu \quad$ dynamic viscosity $(\mathrm{kg} / \mathrm{m} / \mathrm{s})$

$M \quad$ mass flow rate $(\mathrm{kg} / \mathrm{s})$

$M_{a} \quad$ saline makeup mass flow $(\mathrm{kg} / \mathrm{s})$

$M_{d} \quad$ disposal mass flow $(\mathrm{kg} / \mathrm{s})$

MW molecular weight $(\mathrm{g} / \mathrm{mol})$

$N \quad$ nth node

$N_{s} \quad$ nth stage

$O A R O$ osmotically assisted reverse osmosis

OPEX operation and maintenance expenditures (\$)

out outlet

$p \quad$ permeate channel

$\pi \quad$ osmotic pressure (bar)

$P \quad$ pressure (bar)

$P_{l} \quad$ pressure drop (bar $\left./ \mathrm{m}\right)$

$Q \quad$ volumetric flow rate $\left(\mathrm{m}^{3} / \mathrm{s}\right)$

$R \quad$ ideal gas constant (L bar $/ \mathrm{mol} / \mathrm{K}$ )

$R_{S} \quad$ solute rejection (-)

Re Reynolds number (-)

$\rho_{w} \quad$ density of water $\left(\mathrm{kg} / \mathrm{m}^{3}\right)$

RO reverse osmosis
$R_{T, \max } \quad$ theoretical recovery rate limit (-)

$S \quad$ structural parameter (microns)

Sch Schmidt number (-)

Sh Sherwood number (-)

SEC specific energy consumption $\left(\mathrm{kWh} / \mathrm{m}^{3}\right)$

$T$ temperature (K)

TFC thin-film composite

$v \quad$ van't Hoff dissociation factor (-)

$X \quad$ salt mass fraction (-)

\section{CRediT authorship contribution statement}

Adam Atia is responsible for conceptualization, methodology, modeling, analysis, and writing and editing the manuscript. Ngai Yin Yip guided and supervised the study and reviewed the technical findings. Vasilis Fthenakis guided, supervised, and acquired funding for this study and reviewed \& edited the manuscript.

\section{Declaration of competing interest}

The authors declare that they have no known competing financial interests or personal relationships that could have appeared to influence the work reported in this paper.

\section{Acknowledgments}

We would like to thank the reviewers for their important comments that improved this work. This material is based upon work supported by the U.S. Department of Energy's Office of Energy Efficiency and Renewable Energy (DOE-EERE) under the Solar Energy Technologies Office (SETO) Award Number DE00008401. This manuscript was prepared as an account of work sponsored by an agency of the United States Government. Neither the United States Government nor any agency thereof, nor any of their employees, makes any warranty, express or implied, or assumes any legal liability or responsibility for the accuracy, completeness, or usefulness of any information, apparatus, product, or process disclosed, or represents that its use would not infringe privately owned rights. Adam A. Atia also acknowledges previous support by the National Science Foundation Graduate Research Fellowship Program under Grant No. DGE-11-44155. Any opinions, findings, and conclusions or recommendations expressed in this material are those of the authors and do not necessarily reflect the views of the Department of Energy or the National Science Foundation.

\section{Appendix A. Supplementary data}

Supplementary data to this article can be found online at https://doi. org/10.1016/j.desal.2021.115069.

\section{References}

[1] E. Jones, M. Qadir, M.T.H. van Vliet, V. Smakhtin, S. Kang, The state of desalination and brine production: a global outlook, Sci. Total Environ. 657 (2019) 1343-1356, https://doi.org/10.1016/j.scitotenv.2018.12.076.

[2] Global water intelligence-DesalData Database. https://www.desaldata.com/, 2019. (Accessed 14 November 2018).

[3] B.D. Stanford, J.F. Leising, R.G. Bond, S.A. Snyder, Chapter 11 inland desalination: current practices, environmental implications, and case studies in Las Vegas, NV, in: I.C.E. and A.I. Schäfer (Ed.), Sustainability Science and Engineering, Elsevier, 2010: pp. 327-350. http://www.sciencedirect.com/science/article/pii/S18712711 09002116 (accessed November 9, 2015).

[4] S. Lattemann, Development of an environmental impact assessment and decision support system for seawater desalination plants. http://resolver.tudelft.nl/uuid:fe 9c27c4-6329-4314-9ae3-5d2e5fc11e28, 2010. (Accessed 18 October 2020).

[5] N. Voutchkov, Water Environment Federation, WateReuse Association, Desalination Engineering: Planning and Design, McGraw-Hill, New York, 2013.

[6] A. Burbano, P. Brankhuber, Demonstration of Membrane Zero Liquid Discharge for Drinking Water Systems-A Literature Review, Water Environment Research Foundation, Alexandria, VA, 2012. 
[7] D.M. Davenport, A. Deshmukh, J.R. Werber, M. Elimelech, High-pressure reverse osmosis for energy-efficient hypersaline brine desalination: current status, design considerations, and research needs, Environ. Sci. Technol. Lett. 5 (2018) 467-475, https://doi.org/10.1021/acs.estlett.8b00274.

[8] C. Boo, R.K. Winton, K.M. Conway, N.Y. Yip, Membrane-less and non-evaporative desalination of hypersaline brines by temperature swing solvent extraction, Environ. Sci. Technol. Lett. 6 (2019) 359-364, https://doi.org/10.1021/acs. estlett.9b00182.

[9] T. Tong, M. Elimelech, The global rise of zero liquid discharge for wastewater management: drivers, technologies, and future directions, Environ, Sci. Technol. 50 (2016) 6846-6855, https://doi.org/10.1021/acs.est.6b01000.

[10] R. Schwantes, K. Chavan, D. Winter, C. Felsmann, J. Pfafferott, Techno-economic comparison of membrane distillation and MVC in a zero liquid discharge application, Desalination. 428 (2018) 50-68, https://doi.org/10.1016/j. desal.2017.11.026.

[11] T.V. Bartholomew, N.S. Siefert, M.S. Mauter, Cost optimization of osmotically assisted reverse osmosis, Environ, Sci. Technol. 52 (2018) 11813-11821, https:// doi.org/10.1021/acs.est.8b02771.

[12] H.W. Chung, K.G. Nayar, J. Swaminathan, K.M. Chehayeb, J.H. Lienhard V, Thermodynamic analysis of brine management methods: zero-discharge desalination and salinity-gradient power production, Desalination. 404 (2017) 291-303, https://doi.org/10.1016/j.desal.2016.11.022.

[13] G. Zaragoza, J.A. Andrés-Mañas, A. Ruiz-Aguirre, Commercial scale membrane distillation for solar desalination, Npj Clean Water 1 (2018) 20, https://doi.org/ 10.1038/s41545-018-0020-z.

[14] H.W. Chung, J. Swaminathan, D.M. Warsinger, J.H. Lienhard V, Multistage vacuum membrane distillation (MSVMD) systems for high salinity applications, J. Membr. Sci. 497 (2016) 128-141, https://doi.org/10.1016/j. memsci.2015.09.009.

[15] E. Drioli, G. Di Profio, E. Curcio, Progress in membrane crystallization, Curr. Opin. Chem. Eng. 1 (2012) 178-182, https://doi.org/10.1016/j.coche.2012.03.005.

[16] R.L. McGinnis, N.T. Hancock, M.S. Nowosielski-Slepowron, G.D. McGurgan, Pilot demonstration of the $\mathrm{NH} 3 / \mathrm{CO} 2$ forward osmosis desalination process on high salinity brines, Desalination. 312 (2013) 67-74, https://doi.org/10.1016/j. desal.2012.11.032.

[17] C. Boo, I.H. Billinge, X. Chen, K.M. Shah, N.Y. Yip, Zero liquid discharge of ultrahigh-salinity brines with temperature swing solvent extraction, Environ, Sci. Technol. 54 (2020) 9124-9131, https://doi.org/10.1021/acs.est.0c02555.

[18] K.G. Nayar, J. Fernandes, R.K. McGovern, B.S. Al-Anzi, J.H. Lienhard, Cost and energy needs of RO-ED-crystallizer systems for zero brine discharge seawate desalination, Desalination. 457 (2019) 115-132, https://doi.org/10.1016/j. desal.2019.01.015.

[19] K.G. Nayar, J. Fernandes, R.K. McGovern, K.P. Dominguez, A. McCance, B.S. AlAnzi, J.H. Lienhard, Cost and energy requirements of hybrid RO and ED brine concentration systems for salt production, Desalination. 456 (2019) 97-120, https://doi.org/10.1016/j.desal.2018.11.018.

[20] T.V. Bartholomew, L. Mey, J.T. Arena, N.S. Siefert, M.S. Mauter, Osmotically assisted reverse osmosis for high salinity brine treatment, Desalination. 421 (2017) 3-11, https://doi.org/10.1016/j.desal.2017.04.012.

[21] C.D. Peters, N.P. Hankins, Osmotically assisted reverse osmosis (OARO): five approaches to dewatering saline brines using pressure-driven membrane processes, Desalination. 458 (2019) 1-13, https://doi.org/10.1016/j.desal.2019.01.025.

[22] A.T. Bouma, J.H. Lienhard, Split-feed counterflow reverse osmosis for brine concentration, Desalination. 445 (2018) 280-291, https://doi.org/10.1016/j desal.2018.07.011.

[23] Z. Wang, A. Deshmukh, Y. Du, M. Elimelech, Minimal and zero liquid discharge with reverse osmosis using low-salt-rejection membranes, Water Res. 170 (2020), 115317, https://doi.org/10.1016/j.watres.2019.115317.

[24] X. Chen, N.Y. Yip, Unlocking high-salinity desalination with cascading osmotically mediated reverse osmosis: energy and operating pressure analysis, Environ, Sci. Technol. 52 (2018) 2242-2250, https://doi.org/10.1021/acs.est.7b05774.

[25] D.M. Davenport, C.L. Ritt, R. Verbeke, M. Dickmann, W. Egger, I.F.J. Vankelecom, M. Elimelech, Thin film composite membrane compaction in high-pressure reverse osmosis, J. Membr. Sci. 610 (2020), 118268, https://doi.org/10.1016/j. memsci.2020.118268.

[26] M.G. Ahunbay, Achieving high water recovery at low pressure in reverse osmosis processes for seawater desalination, Desalination. 465 (2019) 58-68, https://doi. org/10.1016/j.desal.2019.04.023.

[27] T.H. Chong, W.B. Krantz, Process economics and operating strategy for the energyefficient reverse osmosis (EERO) process, Desalination. 443 (2018) 70-84, https:// doi.org/10.1016/j.desal.2018.05.007.

[28] M.G. Ahunbay, S.B. Tantekin-Ersolmaz, W.B. Krantz, Energy optimization of a multistage reverse osmosis process for seawater desalination, Desalination. 429 (2018) 1-11. doi:https://doi.org/10.1016/j.desal.2017.11.042.

[29] K. Park, D.Y. Kim, D.R. Yang, Cost-based analysis about a newly designed twostaged reverse osmosis process with draw solute, in: Z. Kravanja, M. Bogataj (Eds.), Computer Aided Chemical Engineering, Elsevier, 2016, pp. 223-228, https://doi. org/10.1016/B978-0-444-63428-3.50042-4.
[30] C.D. Peters, N.P. Hankins, The synergy between osmotically assisted reverse osmosis (OARO) and the use of thermo-responsive draw solutions for energy efficient, zero-liquid discharge desalination, Desalination. 493 (2020), 114630, https://doi.org/10.1016/j.desal.2020.114630.

[31] X. Chen, C. Boo, N.Y. Yip, Transport and structural properties of osmotic membranes in high-salinity desalination using cascading osmotically mediated reverse osmosis, Desalination. 479 (2020), 114335, https://doi.org/10.1016/j. desal.2020.114335.

[32] J. Martínez, E. León, F.M. Baena-Moreno, M. Rodríguez-Galán, F. Arroyo-Torralvo, L.F. Vilches, Techno-economic analysis of a membrane-hybrid process as a novel low-energy alternative for zero liquid discharge systems, Energy Convers. Manag. 211 (2020), 112783, https://doi.org/10.1016/j.enconman.2020.112783.

[33] N.Y. Yip, M. Elimelech, Performance limiting effects in power generation from salinity gradients by pressure retarded osmosis, Environ, Sci. Technol. 45 (2011) 10273-10282, https://doi.org/10.1021/es203197e.

[34] J.D. Hedengren, R.A. Shishavan, K.M. Powell, T.F. Edgar, Nonlinear modeling, estimation and predictive control in APMonitor, Comput. Chem. Eng. 70 (2014) 133-148, https://doi.org/10.1016/j.compchemeng.2014.04.013.

[35] T.V. Bartholomew, M.S. Mauter, Computational framework for modeling membrane processes without process and solution property simplifications, J. Membr. Sci. 573 (2019) 682-693, https://doi.org/10.1016/j. memsci.2018.11.067.

[36] A. Deshmukh, N.Y. Yip, S. Lin, M. Elimelech, Desalination by forward osmosis: identifying performance limiting parameters through module-scale modeling, J. Membr. Sci. 491 (2015) 159-167, https://doi.org/10.1016/j. memsci.2015.03.080.

[37] B.V. der Bruggen, Nanofiltration, in: Encyclopedia of Membrane Science and Technology, American Cancer Society, 2013, pp. 1-23, https://doi.org/10.1002/ 9781118522318.emst077.

[38] R.W. Baker, Membrane Technology and Applications, John Wiley \& Sons, 2012.

[39] J.R. Werber, A. Deshmukh, M. Elimelech, The critical need for increased selectivity, not increased water permeability, for desalination membranes, Environ. Sci. Technol. Lett. 3 (2016) 112-120, https://doi.org/10.1021/acs. estlett.6b00050.

[40] NREL, Annual Technology Baseline, National Renewable Energy Laboratory, Golden, CO, 2020, 2020, https://atb.nrel.gov/. (Accessed 15 December 2020).

[41] H.T. El-Dessouky, H.M. Ettouney, Chapter 7 - reverse osmosis, in: H.T. ElDessouky, H.M. Ettouney (Eds.), Fundamentals of Salt Water Desalination, Elsevier Science B.V., Amsterdam, 2002: pp. 409-437. http://www.sciencedirect.com/sci ence/article/pii/B9780444508102500099 (accessed June 30, 2014).

[42] S.J. Kwon, K. Park, D.Y. Kim, M. Zhan, S. Hong, J.-H. Lee, High-performance and durable pressure retarded osmosis membranes fabricated using hydrophilized polyethylene separators, J. Membr. Sci. 619 (2021), 118796, https://doi.org/ 10.1016/j.memsci.2020.118796.

[43] G.M. Geise, H.B. Park, A.C. Sagle, B.D. Freeman, J.E. McGrath, Water permeability and water/salt selectivity tradeoff in polymers for desalination, J. Membr. Sci. 369 (2011) 130-138, https://doi.org/10.1016/j.memsci.2010.11.054.

[44] Y.-M. Tu, W. Song, T. Ren, Y. Shen, R. Chowdhury, P. Rajapaksha, T.E. Culp, L. Samineni, C. Lang, A. Thokkadam, D. Carson, Y. Dai, A. Mukthar, M. Zhang, A. Parshin, J.N. Sloand, S.H. Medina, M. Grzelakowski, D. Bhattacharya, W. A. Phillip, E.D. Gomez, R.J. Hickey, Y. Wei, M. Kumar, Rapid fabrication of precise high-throughput filters from membrane protein nanosheets, Nat. Mater. 19 (2020) 347-354, https://doi.org/10.1038/s41563-019-0577-z.

[45] Q. She, X. Jin, C.Y. Tang, Osmotic power production from salinity gradient resource by pressure retarded osmosis: effects of operating conditions and reverse solute diffusion, J. Membr. Sci. 401-402 (2012) 262-273. doi:https://doi.org/10 .1016/j.memsci.2012.02.014.

[46] A.P. Straub, N.Y. Yip, M. Elimelech, Raising the bar: increased hydraulic pressure allows unprecedented high power densities in pressure-retarded osmosis, Environ. Sci. Technol. Lett. 1 (2014) 55-59, https://doi.org/10.1021/ez400117d.

[47] H. Zhang, G.M. Geise, Modeling the water permeability and water/salt selectivity tradeoff in polymer membranes, J. Membr. Sci. 520 (2016) 790-800, https://doi. org/10.1016/j.memsci.2016.08.035.

[48] H.B. Park, J. Kamcev, L.M. Robeson, M. Elimelech, B.D. Freeman, Maximizing the right stuff: the trade-off between membrane permeability and selectivity, Science. 356 (2017), https://doi.org/10.1126/science.aab0530.

[49] D.M. Warsinger, E.W. Tow, K.G. Nayar, L.A. Maswadeh, J.H. Lienhard V, Energy efficiency of batch and semi-batch (CCRO) reverse osmosis desalination, Water Res. 106 (2016) 272-282, https://doi.org/10.1016/j.watres.2016.09.029.

[50] J.R. Werber, A. Deshmukh, M. Elimelech, Can batch or semi-batch processes save energy in reverse-osmosis desalination? Desalination. 402 (2017) 109-122, https://doi.org/10.1016/j.desal.2016.09.028.

[51] A.A. Atia, V. Fthenakis, Active-salinity-control reverse osmosis desalination as a flexible load resource, Desalination. 468 (2019), 114062, https://doi.org/ 10.1016/j.desal.2019.07.002.

[52] M.S. Mauter, P.S. Fiske, Desalination for a circular water economy, Energy Environ, Sci. (2020), https://doi.org/10.1039/D0EE01653E. 